Open Access

\title{
A methodological framework for futures studies: integrating normative backcasting approaches and descriptive case study design for strategic data-driven smart sustainable city planning
}

Simon Elias Bibri ${ }^{1,2}$

\author{
Correspondence: simoe@ntnu.no \\ 'Department of Computer Science, \\ The Norwegian University of \\ Science and Technology, Sem \\ Saelands veie 9, NO-7491 \\ Trondheim, Norway \\ ${ }^{2}$ Department of Architecture and \\ Planning, The Norwegian University \\ of Science and Technology, Alfred \\ Getz vei 3, Sentralbygg 1, 5th floor, \\ NO-7491 Trondheim, Norway
}

\begin{abstract}
Originally proposed as an alternative to traditional energy planning methodology in the 1970s, backcasting is increasingly applied in futures studies related to sustainability, as it is viewed as a natural step in operationalizing sustainable development. This futures study is concerned with data-driven smart sustainable urbanism as an instance of sustainable urban development-a strategic approach to achieving the long-term goals of urban sustainability. This is at the core of backcasting, which typically defines criteria for a desirable (sustainable) future and builds a set of feasible and logical pathways between the state of the future and the present. This paper reviews, discusses, and justifies the methodological framework applied in the futures study. This aims to analyze, investigate, and develop a novel model for data-driven smart sustainable cities of the future as a form of transformative change towards sustainability. This paper corroborates that the backcasting approach — as applied in the futures study —is well-suited for long-term urban problems and sustainability solutions due to its normative, goal-oriented, and problem-solving character. It also suggests that case study research is the most effective way to underpin and increase the feasibility of future visions. Indeed, the case study approach as a research strategy facilitates the investigation and understanding of the underlying principles in the real-world phenomena involved in the construction of the future vision in the backcasting study. The novelty of this work lies in the integration of a set of principles underlying several normative backcasting approaches with descriptive case study design to devise a framework for strategic urban planning whose core objective is clarifying which city model is desired and working towards that goal. Visionary images of a long-term future based on normative backcasting can spur innovative thinking about and accelerate the movement towards sustainability. The proposed framework serves to help researchers in analyzing, investigating, and developing future models of sustainable urbanism, smart urbanism, and smart sustainable urbanism, as well as to support policymakers and facilitate and guide their actions with respect to transformative changes towards sustainability based on empirical research.

(Continued on next page)
\end{abstract}


(Continued from previous page)

Keywords: Normative backcasting, Descriptive case study, Futures studies, Data-driven smart sustainable cities, Strategic planning, Energy planning, Methodology

\section{Introduction}

In recent years, there has been a conscious push for sustainable cities across the globe to be smarter and thus more sustainable by developing and implementing data-driven technology solutions so as to optimize and enhance their operations, functions, services, designs, strategies, and policies in line with the vision of sustainability. Big data technologies are becoming essential to the functioning of sustainable cities (e.g., Bibri 2018a, b, 2019a, b, 2020a, b, c, d; Bibri and Krogstie 2017a, b, 2018, 2020a; Pasichnyi et al. 2019; Shahrokni et al. 2014a, b, 2015a, b; Sun and Du 2017). Consequently, a new era is presently unfolding wherein sustainable urban development processes and practices are being highly responsive to a form of data-driven urbanism under what is labelled "data-driven smart sustainable cities."

As an emerging paradigm of urbanism, data-driven smart sustainable cities represents an instance of sustainable urban development, a strategic approach to achieving the long-term goals of urban sustainability-with support of advanced Information and Communication Technology (ICT), notably the Internet of Things (IoT) and big data technologies and their novel applications. Achieving the status of data-driven smart sustianable cities of the future in turn epitomizes an instance of urban sustainability. This notion denotes a desired (normative) state in which a city retains a balance of the socio-ecological systems through adopting and executing sustainable development strategies as a desired (normative) trajectory (Bibri and Krogstie 2019a, b). This balance entails continuously improving and advancing the environmental, economic, social, and physical systems of the city over the long run-given their interdependence, synergy, and equal importance. This strategic long-term goal requires fostering linkages between scientific research, technological innovation, policy analysis, institutional practices, planning strategies, and development projects and initiatives in relevance to sustainability. It also requires a long-term vision, an interdisciplinary and trans-disciplinary approach, and a system-oriented perspective. All these requirements are at the core of the normative backcasting approach to futures studies, which facilitates and contributes to the planning, design, development, implementation, evaluation, improvement, and advancement of data-driven smart sustianable cities of the future as a new integrated model of urbanism. The focus of the futures study is on the planning, design, and development aspects of the goal-oriented backcasting process. One of the most enticing areas of research within urban sustainability is that which is concerned with normative backcasting-oriented futures studies. The relevance and rationale for adopting the normative backcasting approach to futures studies stems from the strategic planning process it entails to achieve the long-term goals of urban sustainability in the form of a vision of a desirable (sustainable) future. Backcasting is well suited to any multifaceted kind of planning process (e.g., Holmberg and Robèrt 2000), as well as to the complex problems of sustainability (e.g., Bibri 2018a, 2018c, 2019a; Carlsson-Kanyama et al. 2003; Höjer et al. 2011; Holmberg 1998; Miola 2008; Quist 2007; Robert et al. 2000). 
An appropriate response to the strategic planning of data-driven smart sustainable cities should involve the analysis of several intertwined elements, including past, present, and future situations; long-term visions; the formulation, implementation, and follow-up of strategies; the execution of specific pathways, the transfer and deployment of technologies; the building and enhancement of human and social capacities; and the design of and compliance with regulatory policies. These elements cannot be isolated from one another in all kinds of urban sustainability efforts. And this is what backcasting entails as applied in the futures study, which aims to analyze, investigate, and develop a novel model for data-driven smart sustainable cities of the future. In so doing, it endeavors to amalgamate the prevailing and emerging paradigms of urbanism in terms of their strategies and solutions in order to a new model of urbanism. This amalgamation is grounded in the outcomes of four case studies, each of which investigates and compares two of a total of six cases from the ecologically and technologically leading cities in Europe: (1) Gothenburg and Helsingborg as compact cities (Bibri et al. 2020) Stockholm and Malmö as eco-cities (Bibri and Krogstie 2020a), (3) London and Barcelona as data-driven smart cities (Bibri and Krogstie 2020b), and (4) Stockholm and Barcelona as environmentally data-driven smart sustainable cities (Bibri and Krogstie 2020c).

The case study research is associated with the empirical phase of the futures study. One important use of case study approach in research is planning, which in turn is at the core of the normative backcasting approach. One of the essential requisites for employing the case study approach stems from one's motivation to illuminate complex phenomena (Merriam 2009; Stake 2006; Yin 2017). The motivation in this context is to integrate the aforementioned leading paradigms of urbanism in terms of their strategies and solutions. The resulting paradigm of urbanism is approached from the perspective of combining the strengths of sustainable cities and smart cities and harnessing their synergies in ways that primarily enable sustainable cities to improve and advance their contribution to the goals of sustainability in the face of the escalating urbanization trend.

In urban research, there are a range of qualitative approaches to data collection and analysis that researchers typically rely on to investigate a wide range of issues related to the environmental, economic, social, physical, spatial, and/or technological dimensions of the city from a wide variety of perspectives. The choice of qualitative approaches as well as their integration in this regard depends largely on what researchers intend to investigate and thus achieve as outcomes.

This paper reviews, discusses, and justifies the methodological framework applied in the futures study. In so doing, it integrates a set of principles underlying several normative backcasting approaches with descriptive case study design to devise a framework for strategic urban planning whose core objective is clarifying which city model is desired and working towards that goal.

This paper is structured as follows: Section 2 describes futures studies in terms of their characteristics, categories, and approaches. Section 3 reviews and discusses backcasting as the overarching approach applied in the futures study. Section 4 reviews and discusses the case study approach related to the empirical phase of the futures study. This paper ends, in Section 5, with concluding remarks and discussion. 


\section{Futures studies}

In recent years, scientists, sociologists, futurists, and researchers within different disciplines have developed qualitative and quantitative methods for rationally predicting the future. Rationality in this context means a recognition or awareness that many different futures are possible, and that the future is far from being determined or known with absolute certainty. This is typically contingent on the kinds of decisions that people make and the kinds of actions they take in the present. Futures studies are intended to assist decision-making under uncertainty which is to be defined as indeterminacy rather than to predict the future (Dreborg 1996). Their primary purpose is to get a better understanding of future opportunities as alternatives with their differences and feasibilities. These can be employed by the aligned stakeholders as part of a given endeavor to challenge present systems, to influence or inspire the future, or to respond to the most likely future to happen. Creating a choice of futures by outlining alternatives usually form the basis for strategic planning. In light of this, futures studies help people to examine and clarify their normative scenarios of the future, to transform their visions, and to develop action plans on the basis of a wide range of techniques.

Long lasting and substantive transformations, such as sustainability transitions, can only come about through the accumulation of a number of integrated smaller-scale actions associated with successful initiatives and programs. They also operate at the interface of policy domains. Methodologies for futures studies can help to highlight these initiatives and programs and to identify such interface. Researchers employ these methodologies as an attempt to manage uncertainty by clarifying what the most desirable possibilities are, what is already known, what can be known, as well as how today's decisions may play out in each of a variety of plausible futures. The effectiveness of futures studies lies in defining a broader conceptual framework for discussing the future and in contributing to policy formulation, transition governance, and the emergence of new possibilities. And the kind of decisions futures studies seek to support under uncertainty pertains particularly to long-term decisions. In the context of the futures study, decisions are to be made in ways that reduce uncertainty about what may happen to sustainable cities in the future in the light of the escalating urbanization trend. This entails analyzing the effects of today's decisions taken in line with the vision of sustainability and supported by big data technologies in the future. The role of futures studies has become of central importance for policymaking in the sphere of urban sustainability. This process is characterized by increasing complexity at the macro-level as well as by decreasing the extent of conditionality at the micro-level due to the mounting autonomy of individual actors. This implies that social institutions are less powerful in affecting major changes through straightforward policy responses (Ling 2002).

Futures studies can be classified based on three modes of thinking about the future (Banister and Stead 2004):

- Possible futures (what might happen?). Scenario studies as descriptions of possible future states and their developments are included in this mode (Börjeson et al. 2006).

- Probable futures (what is most likely to happen?). This includes forecasting studies, which are characterized by a predictive nature and mainly focused on historical data and trend analysis. 
- Preferable futures (what we would prefer to happen?). This mode is of relevance to futures studies dealing with sustainability as it focuses on desirable futures, such as backcasting and normative forecasting.

Several authors have elaborated on futures studies in relation to sustainability. Dreborg (1996) identifies four different types of futures studies in connection with sustainability, namely:

1. Directional studies which investigate different economics and other measures in the short-term that will probably work in the right direction towards sustainability.

2. Short-term studies which take immediate official goals as a starting point or a small step towards sustainability, and attempt to find means of achieving them.

3. Forecasting studies which usually apply to a long-term perspective, but restricted presumptions of the possibilities of major change make this approach fail to reach sustainability.

4. Alternative solutions and visions where the development of future (normative) scenarios as desirable futures allows them to be explored by using backcasting where the results describe a desirable future with criteria for sustainability providing the systemic framework for change.

In the framework of the futures study, the backcasting approach is prescriptive in the sense of focusing on what the data-driven smart sustainable city of the future should be. Generally, prescriptive (normative) approaches to futures studies try to aid people in clarifying their values and preferences so they can develop visions of desirable futures. Approaches to futures studies are also descriptive (extrapolative) in the sense of describing what the future will be or could be in an objective way. While many futurists strive for objectivity, most approaches to futures studies as part of qualitative inquiry rely on subjective human judgment. Nevertheless, various tools have been developed and applied to mitigate this bias through encouraging collective judgment, generating ideas to produce different judgments, and identifying discrepancies between competing views on the future, as well as substantiating consistencies and inconsistencies among and within these views (Bibri 2018c).

There could be as many approaches to futures studies as futurists because they tend to develop different ways to look ahead or to envision the future. However, according to Chatterjee and Gordon (2006), futures studies can be categorized on the basis of the context that is being studied in terms of simplicity and complexity. Specifically, if the context is predictable and largely controllable then a planning approach such as forecasting may be appropriate, and if it is unpredictable and uncertain an alternative approach such as scenario planning is more suitable (Chatterjee and Gordon 2006). Another consensual perspective among futurists is the need to employ multiple approaches to address futures problems. In the futures study, the intent is to use backcasting as a planning approach which is complemented by insights drawn from trend analysis and scenario planning methods. There is an argument that supports the idea of developing future research programs that integrate various approaches to futures studies to gain much greater insight than relying on a single approach. There are a number 
of different approaches to strategy analysis and future analysis that investigate what will, could, or should happen in the future that are in their application not mutually exclusive. These approaches include, but not limited to, cyclical pattern analysis, trend analysis, visioning, scenario planning, in addition to backcasting and forecasting. For a descriptive account of these approaches, which can be combined in futures studies, the interested reader can be directed to Bibri (2018c).

Researchers often need different approaches to carry out their futures studies. In this line of thinking. Höjer and Mattsson (2000) suggest that backcasting and regular forecasting are complementary rather than conflicting opposites. They add a forecasting step to the backcasting approach where forecasts and the desired vision are compared. If the vision is unlikely to be reached based on the most reliable forecasts, model calculations, and other estimates, backcasting studies should be used to generate images of the future that fulfil the targets. They also emphasize the importance of scrutinising how to attain the desirable future by working back from the desirable future to check the physical and social feasibility of the pathway towards that future. This requires not only identifying the necessary measures and actions for bringing about that future, but also using models and regular forecasting tools to quantify the consequences of different measures and actions.

In sum, there is no general consensus on a single classification of futures studies, nor a guide for the application of the most suitable approaches to futures studies. The researcher's worldview and aim are the most important criteria that determine how a futures study can be conducted and which approach should be applied to achieve its aim.

\section{Backcasting}

\section{Backcasting in energy and sustainability studies: a brief history}

The origin of backcasting dates back to the 1970s, when backcasting was proposed as an alternative planning methodology for electricity supply and demand (Robinson 1982). Robinson (1982) proposed the term "energy backcasting," assuming that future energy demand is mainly a function of current policy decisions. The futures studies concerned with energy had dealt with the so-called soft energy policy paths, characterized by the development of renewable energy technologies and a low-energy demand society (Quist and Vergragt 2006). At the time, they emerged as a response to regular energy forecasting, which was mainly based on trend extrapolation and projections of energy consumption, with a focus on large-scale fossil fuel and nuclear energy. The focus of energy backcasting was on analysis and on developing policy goals. Also, the backcasts of different alternative energy futures were meant to reveal the relative implications of different policy goals (Robinson 1982), and to determine the possibilities and opportunities for policy-making. Robinson (1990) emphasises that the purpose of backcasting is to indicate the relative feasibility and different social, environmental, and political implications of different energy futures. Recently, Anderson (2001) has adapted the energy backcasting approach, with the aim of reconciling the energy industry with sustainable development. This approach takes into account wider environmental and social responsibilities, as well as non-expert knowledge, and includes the development of supporting policies. In sum, the early focus in backcasting was on exploring and assessing energy futures and on their potential for policy analysis in the traditional 
sense of supporting policy and policymakers, usually adopting a government-oriented perspective.

After the widespread diffusion of sustainable development in the early 1990s, it was realized that the backcasting approach could potentially be applied to a wide range of sustainability-related subjects. Robinson (1990) marked the move towards the application of backcasting to sustainability and illustrated the interest in Sweden, as the work reported on a study supported by the Swedish energy research council. Following the strategic interest in alternative energy futures and the increasing ecological disruption in Sweden from the early 1980s onward (Mol 2000), substantial efforts were made for developing the concept of backcasting for sustainability (e.g., Dreborg 1996; Holmberg 1998; Höjer and Mattsson 2000). Backcasting for sustainability has been applied in Sweden on a range of topics, including sustainable transportation systems (Akerman and Höjer 2006; Höjer and Mattsson 2000), sustainable air transport (Åkerman 2005), GHG emissions (Höjer et al. 2011), sustainable transformation of companies (Holmberg 1998), and sustainable city design (Carlsson-Kanyama et al. 2003). A number of other studies have been conducted in other countries, especially Europe, with respect to alternative scenarios and solutions pertaining to such topics as transportation and mobility (Banister et al. 2000), sustainable technologies and sustainable system innovation (Weaver et al. 2000), sustainable household (Green and Vergragt 2002; Quist et al. 2001), and so on. For a more detailed overview of past and present applications of backcasting, the interested reader can be directed to Quist and Vergragt (2006). However, the distinctive nature of backcasting makes it appropriate for sustainability applications. Dreborg (1996) argues that, due to their normative and problem-solving character, backcasting approaches are much better suited to address long-term problems and sustainability solutions. This mainly has to do with the idea of taking desirable futures or a range of sustainable futures as a starting point for analysing their potential and feasibility, as well as the possible ways of achieving them.

In recent years, however, backcasting has become the most commonly applied approach in futures studies dealing with urban sustainability, thereby its relevance and appropriateness for data-driven smart sustainable urbanism as a form of transformative change towards sustainability. Researchers from the fields of smart cities, sustainable cities, and smart sustainable cities alike have endeavored to understand and act according to the goals of sustainability by describing visionary scenarios of a long-term future and justifying their potential attainment based on a varied set of established theories and academic disciplines and discourses in conjunction with in-depth analyses of case studies in a bid to accelerate the movement towards sustainability. This implies that a large body of research within these fields has been, and will be, formed by and founded on backcasting-oriented futures studies of different categories and on a wide variety of topics. One strand of futures studies concerns itself with the ways contemporary cities integrate the objectives and targets of sustainable development and those of smart growth in an integrated approach due to the synergetic, substantive, and disruptive effects of advanced ICT, particularly big data technologies. These effects are associated with the operational functioning, management, and planning required for future forms of urban sustainability. The evolving body of futures studies in this direction constitutes a strategic resource for understanding and unlocking the untapped potential of 
advanced ICT as an enabling, integrative, and constitutive set of technologies for improving and advancing sustainability.

\section{Backcasting and strategic sustainable development: a scientific perspective}

The concept of backcasting is central to the strategic approach to sustianable development. Backcasting from the system conditions of sustainability is a key concept of the Framework for Strategic Sustainable Development (FSSD) pioneered by Karl-Henrik Robèrt, founder of The Natural Step (TNS), an international nonprofit organization dedicated to applied research for sustainability in cooperation with a global academic Alliance for Strategic Sustainable Development linking universities that cooperate with industries and businesses. Backcasting from the principles of sustainability is the primary context under which the TNS Framework and the Strategic Approach to Sustainable Development (SASD) have become powerful tools for strategic planning.

Sustainable development as a strategic approach to achieving the goals of sustainability is guided by a shared understanding of the principles of sustainability that embody the end goal of sustainability. The four sustainability principles are considered as basic principles for socio-ecological sustainability as developed through scientific consensus (Holmberg and Robèrt 2000). In the sustainable society, according to Holmberg and Robèrt (2000), nature is not subject to systematically increasing ...

1. ... concentrations of substances extracted from the Earth's crust,

2. ... concentrations of substances produced by society,

3. ... degradation by physical means, and in that society ...

4. people are not subject to conditions that systematically undermine their ability to meet their needs.

The purpose of articulating sustainability with scientific rigor (Clark 2007; Clark and Dickson 2003; Kates et al. 2001) is to make it more intelligible and more useful for measuring, analyzing, and managing human activities within society. A significant contribution in this line was the development of the aforementioned guiding sustainability principles. The sustainability principles should be, according to Holmberg and Robèrt (2000, p. 298):

- Based on a scientifically agreed upon view of the world

- Necessary to achieve sustainability

- Sufficient to achieve sustainability

- General to structure all societal activities relevant to sustainability

- Concrete to guide action and serve as directional aides in problem analysis

- Non-overlapping or mutually exclusive in order to enable comprehension and structured analysis of the issues.

In the framework of the futures study, sustainability principles define an end goal for urban sustainability to plan holistically in relation to urban development to ultimately achieve a balance of the socio-ecological systems in the data-driven smart sustainable city of the future. Strategic sustainable urban development is a planned development 
that seek to address and overcome the physical, environmental, economic, and social challenges of sustainable cities in ways that continuously enhance their performance in a rigorous, meaningful, and scientific way. This requires developing upstream solutions necessary to sustain the functioning of the city systems and making them more resilient over the long run.

Generally, the link between sustainable development and science stems from the idea that the former is an aspiration that should, as realized by several scholars over the past two decades, be achieved only on the basis of scientific knowledge. This has justified the establishment of a new branch of science due to the fact that, arguably, humanity is confronted at an ever unprecedented rate and larger scale with the ramifications of its own success as a species. The way things have changed in recent years (and the attempts being undertaken to take this into account) calls for a scientific approach to understanding the underlying web of ongoing, reciprocal relationships generating the patterns of behavior that the ecosystems are exhibiting, and to figure out the mechanisms these ecosystems are using to control themselves. The point is that the complexities, uncertainties, and hazards of the human adventures are triggering unparalleled changes increasingly requiring insights from all the sciences to tackle them if there is a shred of seriousness about the aspiration to enhance and sustain the quality of life. The real challenge emanating from the fragmented character of science lies in understanding and acting upon the causal mechanisms and behavioral patterns in response to the reciprocal relationships between different complex systems across several time and space scales. This calls for fusing disciplines, a transdisciplinary approach that reconciles and fuses the theoretical and practical knowledge, the quantitative and qualitative perspectives, and the natural and social sciences. Sustainability science is what such an integrative approach entails, and whose emphasis is on understanding changes in states rather than just their characterization. Systems theory and system analysis approaches have become the most coherent expression of this insight (Bossel 2004). Sustainability science is perhaps the most clear and desirable illustration of the endeavor of reinforcing the unified approaches and unifying tendencies in science, as well as of liberating the study of real-world processes from the boundaries between the scientific disciplines (de Vries 2013).

The quest for finding an urban development planning approach that can accommodate the wicked problems of cities, especially in relation to sustainability and urbanization, and overcome the complexity and unpredictability introduced by socio-political factors is increasingly inspiring scholars to combine urban sustainability and sustainability science under what has recently been termed "urban sustainability science." (Bibri 2019c). This term is informed by urban science, a field in which big data science and analytics is practiced, which in turn informs and sustains data-driven smart urbanism. Data-intensive science is transforming urban science and sustainability science and the way they inform urban sustainability. The objective of urban sustainability is to uphold the changing dynamics and thus reciprocal relationships (within and across levels and scales) that maintain the ability of cities to provide not just life-supporting, but also life-enhancing, conditions, exhibited by their collective behavior as complex systems.

The understanding of the city as an instance of socio-ecological systems based on sustainability science principles using a data-driven analytical approach can help address and overcome the challenges associated with the wicked problems related to 
urban planning and development in the context of sustainability. There is a host of new practices that sustainability science could bring to urban sustainability under the umbrella of data-intensive science, an argument that needs to be developed further and to become part of mainstream debates in urban research, practice, and policy (Bibri 2019c, 2020a). This argument is being stimulated by the ongoing discussion and development of the new ideas about the untapped potential of big data science and analytics for advancing sustainability science and urban sustainability, as well as merging them into a holistic framework informed by urban science as a field where data science can be practiced. Urban sustainability science as a research field seeks to give the broad-based and crossover approach of urban sustainability a solid scientific foundation.

\section{Distinctive characteristics of backcasting}

The term "backcasting," can denote a concept, a study, an approach, a methodology, a framework, or an interactive process among stakeholders. Therefore, it has been defined in multiple ways. Robinson (1990), p. 823 defines backcasting as a normative approach which works "backwards from a particular desired end point to the present in order to determine the feasibility of that future and what policy measures would be required to reach that point." Backcasting is a way of planning in which a successful outcome is imagined in the future, followed by the question: "what do we need to do today to reach that successful outcome?" This is more useful than forecasting, which tends to present a more limited range of options and projects the problems of today into the future. Backcasting is used in cases where it is desired to actively dictate a future outcome rather than predicting it, and also where existing trends are leading to an unfavourable state.

Backcasting is applicable in those futures studies that address the fundamental question of backcasting: "if we want to attain a certain goal, what actions must be taken to get there?" As such, it is about looking at the current situation from a future perspective. However, it is as crucially important to undertake the next steps as having lofty visions, thereby sustaining momentum by explicit shared visions of success and being able to use that to guide the next steps.

Furthermore, since backcasting deals with images of the future rather than reality, it is by definition normative, implying a certain desired view. Concerned with human societies, normativity is the phenomenon of designating some desirable or permissible actions. Researchers tend to restrict the use of the term "normative" to the evaluative sense. In consultation exercises as part of the normative-oriented visionary model of scenario construction, further insights can be gained by comparing different normative scenarios generated by different stakeholders.

\section{Normative scenarios}

In recent years, the backcasting-oriented futures studies have received more prominence in the domain of sustainability. A general purpose of futures studies is to explore possible, probable, and preferable futures by imagining the possible, assessing the probable, and deciding on the preferable. The futures study is concerned with the preferable future with respect to urban sustainability as a form of societal transition. To facilitate 
the understanding of the underlying logic of large-scale societal transitions towards sustainability, different types of future scenarios are often employed. Börjeson et al. (2006) categorize scenarios as explorative, predictive, or normative. Rotmans et al. (2001) classify scenarios as projective and prospective, qualitative and quantitative, participatory and expert, and descriptive and normative. The latter take values and interests into account and involve reasoning from a set of specific long-term goals that need to be achieved. The futures study applies backcasting as a normative scenario methodology to build a novel model for data-driven smart sustainable cities of the future, which can be used as a planning tool for facilitating the transition towards urban sustainability. Normative scenarios are also called desirable futures or future visions.

Furthermore, due to its goal-oriented and problem-solving nature, backcasting is especially well equipped to be applied to, or well-suited for, long-term sustainability problems (e.g., Bibri 2018c; Dreborg 1996; Holmberg 1998; Quist 2007; Robert et al. 2000). Generally, as argued by Dreborg (1996), backcasting is particularly useful when:

- The problem to be studied is complex and there is a need for major change;

- The dominant trends are part of the problem;

- The problem is a matter of externalities; and

- The scope is wide enough and time horizon is long enough to leave considerable room for deliberate and different choices and directions of development.

Many authors have justified the need for this normative scenario approach by referring to emerging disruptions in societal development (Dreborg 1996; Quist and Vergragt 2006). This is associated with, in the context of this paper, big data science and analytics and its role in improving and advancing sustainability within the framework of sustainable cities as a social organization.

Backcasting scenarios, whether based on quantitatively and qualitatively defined goals, are used to explore future uncertainties, create opportunities, build capabilities, guide policy actions, and enhance decision-making processes. As such, they allow for new options to be considered reasonable, thereby widening the perception of what could be feasible and realistic in the long-term (e.g., Dreborg 1996; Höjer and Mattsson 2000). In the framework of the futures study, they aid strategic urban actors in broadening their perspective on how sustainable cities could enhance and optimize their performance with support of big data technologies and their novel applications in the face of the escalating urbanization trend. In this respect, they describe alternative futures and develop strategies and pathways through which these futures can eventually be achieved. Hence, they are constructed from the distant future towards the present.

\section{The backcasting process}

Backcasting has attracted attention from policy-makers, organizations, and scientific communities due to its benefits for facilitating society-wide transformations. Backcasting works through envisioning and analyzing sustainable futures and then developing strategies and pathways to get there. Once the future desired conditions are imagined and articulated, the necessary steps are defined and pursued to attain those conditions. Backcasting is the process of generating a desirable future and then looking backwards 
to the present in order to determine the strategic actions needed to reach that specified future (Fig. 1). The first part of the process concerns the normative side of backcasting and the second part pertains to the analytical side of backcasting: both the possible ways of reaching certain futures as well as their feasibility and potential. Dreborg (1996) relates backcasting to Constructive Technology Assessment (CTA). The purpose of CTA is to broaden the technology development processes and the debate about technology with environmental and social aspects, as well as to enhance the participation of social actors. A distinction can be drawn between the analytical side and the constructive and process-oriented side of backcasting (Dreborg 1996). With respect to the analytical side, the main result of backcasting studies are alternative images of the future, thoroughly analyzed in terms of their feasibility and consequences. Concerning the constructive-oriented side, backcasting studies should provide an input to a policy developing process in which relevant actors should be involved. However, while imagining a desirable future can inspire strategies and actions, the path to success is not always obvious or straightforward. Nonetheless, the guiding images of the future tend to coalesce and together steer the trajectory of where we are headed-even if we don't arrive exactly where planned and when. This trajectory is usually based on reacting to current circumstances, expert knowledge, creativity, intuition, and common sense, but also needs to be conceivably aligned with the state of the future.

Developing pathways-course of actions, agendas, events, conditions, and triggers-in the framework of backcasting allows to imagine the impacts of future visions, which should accordingly be highly significant and require extensive improvements compared to or in relation to the current trends. In this sense, they should dovetail with the notion of urban sustainability - as a desired state of the future in which the city achieves a balance between environmental protection and integration, economic development and regeneration, social equity and stability, and physical robustness and resilience as long-term goals through the strategic process of sustainable urban development as a desired trajectory.

\section{The normative side of backcasting - the future vision}

Without first defining a future landing place, reaching urban sustainability is an unlikely outcome of any effort.The backcasting approach aids in identifying the strategies

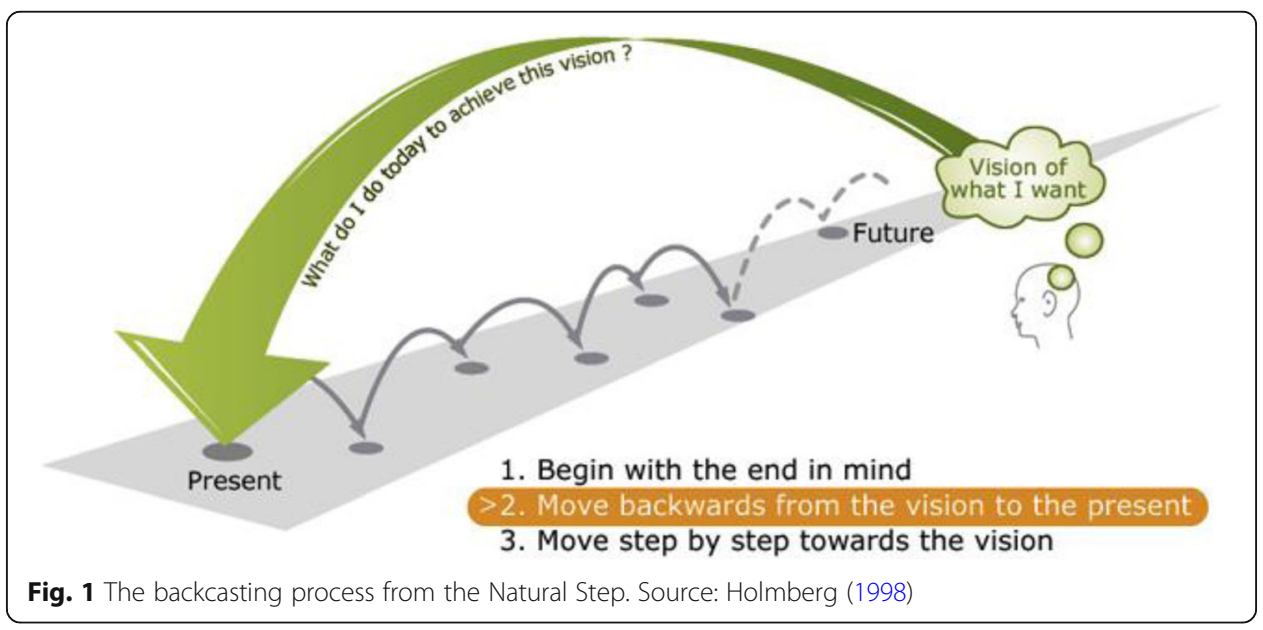


and pathways to be pursued to achieve the objectives and targets of sustainable development and thus the overall goal of the future vision. As a key part of the backcasting process of strategic planning, the future vision should be aligned with sustainability principles and values. As such, it depicts the city of the future as a city which retains a balance between the environmental, economic, and social dimensions of sustainability over the long run with the support of emerging and future technologies. Accordingly, the data-driven smart sustainable city is envisioned as (Bibri and Krogstie 2020c):

A form of human settlements that secures and upholds environmentally sound, economically viable, and socially beneficial development through the synergistic integration of the more established strategies of sustainable cities and the more innovative solutions of data-driven smart cities towards achieving the long-term goals of sustainability.

The generation of the future vision is performed after analyzing the situation related to the current model of urbanism and the main prevailing trends and expected developments pertaining to the future model of urbanism. While some views defend that a prior evaluation grounds the vision in realism, other argue that it curtails the ability to think of "ideal states" by putting the current circumstances and capabilities at the center of attention. In the framework of the futures study, the vision of the future is based on a sequential progression--yet with sharp transformation-- into the future of the prevailing trends and expected developements and the way they intertwine with and affect one another in relation to data-driven smart sustainable cities as a holistic approach. In short, it is based on a combination of technological innovations and sustainability advancements as a co-evolutionary process.

Furthermore, the future vision is in line with the sustainable development goal 11 (SDG 11) of the United Nations' 2030 Agenda-to make cities sustainable, resilient, inclusive, and safe (United Nations 2015a). The 2030 Agenda regards ICT as a means to promote socio-economic development and protect the environment, increase resource efficiency, achieve human progress and knowledge in societies, upgrade legacy infrastructure, and retrofit industries based on sustainable design principles (UN 2015b). Therefore, the multifaceted potential of the smart city approach has been under investigation by the UN (2015c) through their study on "Big Data and the 2030 Agenda for Sustainable Development."

In view of the above, the backcasting approach entails identifying the nature and scope of the problems, issues, and challenges pertaining to sustainable cities with respect to their contribution to sustainability, and then proposing the innovative applied data-driven solutions of smart cities to develop a new paradigm of urbanism: data-driven smart sustainable cities of the future. In so doing, it sets the conditions for mitigating the extreme fragmentation of and the weak connection between sustainable cities and smart cities on the basis of the IoT and big data technologies and their novel applications.

\section{The analytical side of backcasting-pathway-oriented category}

The development of strategies and pathways to the future has long been the subject of futures studies, especially through the construction of future visions or alternative 
scenarios to achieve the goals of sustainability. Typically, backcasting defines criteria for a desirable future and builds a feasible and logical path between the state of the future and the present. The latter allows to set priorities, develop alternative solutions, and determine the strategic actions that need to be taken in order to reach a desirable future. This relates in this context to the backwards-lookinganalysis (Step 6) of the backcasting study, which is concerned with developing strategies and pathways to attain a single desirable future. Worth pointing out is that the backcasting approach is traditionally based on one normative vision, but multiple visions can also be used to explore different future alternatives (e.g., Tuominent et al. 2014).

There are several categories of backcasting. Wangel (2011) classifies backcasting into target-oriented backcasting (what can change); pathway-oriented backcasting (how to change); action-oriented backcasting (who could make change happen); and participation-oriented backcasting (to enhance participation and buy-in by stakeholders). The futures study is concerned with the pathway-oriented backcasting category where the focus is on how the changes can take place and the measures that support those changes. In this category, the setting of strict goals is considered less important (Vergragt and Quist 2011; Wangel 2011) compared to other categories. The pathway-oriented backcasting usually helps identify critical non-technical triggering measures. This is at the core of Step 6 of the futures study, which involves developing a series of planning measures and actions pertaining to urban design strategies, data-driven technology solutions, and sustainability targets and objectives that could be implemented in the near future. Accordingly, in the quest for the answer to how to reach the future vision, the strategies and pathways developed are intended to link the goals that may lie far ahead in the future to the decisive steps that are to be designed and taken now to achieve those goals.

\section{Comparison of backcasting methodologies}

It has been argued in the literature that conventional backcasting methodologies/ approaches or some aspects of them have to be combined in futures studies. The data-driven smart sustainable city of the future integrates sustainable development, technological development, and urban planning, forming an interdisciplinary and transdisciplinary area of urbanism. This implies that a more appropriate backcasting approach as a strategic roadmap to data-driven smart sustainable urbanism as a form of transformational change should draw on insights from three relevant backcasting methodologies, namely Robinson's, TNS, and Sustainable Technology Development (STD). These are shown in Table 1 and compared in terms of their key assumptions and examples of methods.

Robinson's (1990) backcasting approach is characterized as normative and design-oriented, aimed at exploring the implications of alternative development paths as well as the underlying values. The approach gives no standard recipe for generating scenarios, but only some helpful guidelines and tools. In more detail, no reference is made to particular methods, but various groups of methods are mentioned, such as different types of scenario impact analyses, modelling, and scenario approaches. The approach does not specify who is responsible for setting the criteria and future goals and how this will be done, nor 
does it include stakeholder participation. It moreover focuses on technical analysis and policy recommendations. It is acknowledged that the analysis must be connected to the policy process, which can be done by involving relevant government agencies as well as the wider public. However, the futures study draw on insights from Steps 1, 2, 3, 5, and 6 in relation to sustainable urban planning.

In Sweden, backcasting has been elaborated as a methodology for strategic planning towards sustainability, which has become known as the TNS framework, It has been advocated and popularized by Karl-Henrik Robèrt, and thoroughly described by Holmberg (1998) as an approach for strategic sustainability planning in organizations that consists of four steps. Underlying this framework is the way of thinking that the future itself cannot be predicted but by viewing the physical principles of the ecosystem, a set of principles that can be set to describe the future sustainable situation. This is based on four system conditions that should be simultaneously valid in a sustainable society (Robert et al. 2000). The futures study is concerned with all four steps while taking the city as a form of social organization. This means that these steps were contextualized to be applicable to the sustainable city.

Table 1 Comparison of three backcasting methodologies and their key assumptions

\begin{tabular}{l} 
Robinson's Methodology \\
\hline Methodological steps \\
1. Determine objectives \\
2. Specify goals, constraints, and targets, and \\
describe present system and specify \\
exogenous variables \\
3. Describe present system and its material \\
flows \\
4. Specify exogenous variables and inputs \\
5. Undertake scenario construction using the \\
specified goals and constraints \\
6. Undertake scenario impact analysis.
\end{tabular}

6. Undertake scenario impact analysis.

Key assumptions

- Criteria for social and environmental desirability are set externally to the analysis

- Goal-oriented

- Policy-oriented

- Design-oriented

- System oriented

TNS Methodology

1. Define a framework and criteria for sustainability

2. Describe the current situation in relation to that framework

3. Envisage a future sustainable situation

4. Find strategies for sustainability

- Decreasing resource usage

- Diminishing emissions

- Safeguarding biodiversity and ecosystems

- Fair and efficient usage of resources in line with the equity principle
STD Methodology

1. Strategic problem orientation

2. Develop sustainable future vision

3. Set out alternative solutions

4. Explore options and identify bottlenecks

5. Select among options and set up action plans 6. Set up cooperation agreements 7. Implement research agenda

- Sustainable future need fulfilment

- Factor 20

- Time horizon of

40-50 years

- Co-evolution of technology and society

- Stakeholder participation

- Focus on realising follow-up

Examples of methods

- Social impact analysis

- Economic impact analysis

- Environmental analysis

- Scenario construction approaches

- System analysis and modelling

- Material flow analysis and modelling
- Creativity techniques

- Strategy development

- Employee involvement

- Employee training
- Stakeholder analysis

- Stakeholder

workshops

- Problem analysis

- External

communication

- Technology analysis

- Construction of

future visions

- System design and analysis 
The STD approach relates to a Dutch government program, which focuses on achieving sustainable need fulfillment in the distant future. It involves a broad stakeholder participation and the use of creativity to reach beyond existing mindsets and paradigms (Quist 2007). It has also been used for the integration of spatial functions. However, the futures study draws on Steps 1-3, which are designed to develop a long-term vision based on a strategic review of how a need might be met in the future in a sustainable way, and backwards-looking analysis is used to set out alternative solutions for sustainable need fulfilment (Weaver et al. 2000). Similarly, the 3 steps were contextualised to be applicable to data-driven technology in relation to sustainable development in the urban context. Here a data-driven smart sustainable city is a city that meets the needs of its present citizens without compromising the ability for other people or future generations to meet their needs, and where advanced ICT, notably big data technology support its endeavor to not exceed local or planetary environmental limits.

Based on the three above backcasting approaches, the key assumptions underlying the backcasting approach applied in the futures study—considering its overall aim-include:

- Decreasing energy usage

- Efficient utilization of resources in line with the equity principle

- Mitigating pollution

- Sustainable future fulfilment of needs

- Safeguarding biodiversity and ecosystem

- Criteria for social and environmental desirability set externally to the analysis

- Goal-oriented

- Policy-oriented

- Design-oriented

- System-oriented

- Time horizon of 25-50 years

- Co-ev.olution of technology and society

\section{The guiding questions for the six steps in the backcasting-oriented futures study}

The literature shows that there are a number of backcasting approaches and methodologies applied in futures studies. While these differ in their steps and thus guiding questions, they tend to share the essentials. The backcasting framework is adaptive in nature based on the specific context under which it is applied, e.g., research projects with different aims, purposes, scopes, complexities, and time horizons, just to name a few. The result is a process that can be considered more as a set of guiding principles, tools, and practices to achieve a certain goal than as a strict adherence to the application of a rigorous method encompassing all the steps involved in a given backcasting methodology. Unlike methodology, a framework is a loose but incomplete structure which leaves room for other practices and tools to be included, but provides much of the process required. Also, the terms "backcasting methodology" and "backcasting approach" are differentiated in the literature. Quist (2007) clearly elaborates that the backcasting methodology should be applied in such concrete cases, whereas the backcasting approach should be used to describe general and more abstract terms. Fundamentally, a backcasting approach involves four steps, namely (Höjer and Mattsson 2000): 
- The setting of a few long-term targets

- The evaluation of each target against the current situation, prevailing trends, and expected developments

- The generation of images of the future that fulfill the targets

- The analysis of images of the future in terms of feasibility, potential, and pathways towards images of the future (Akerman and Höjer 2006).

Different backcasting approaches are emerging in the field of urban sustainability as to its various domains (e.g., transport, mobility, energy, environment, design, and technology). In this light, Bibri (2018c) synthesizes a backcasting approach to smart sustainable city development based on the review of a number of futures studies using different backcasting approaches and methodologiesn, and later, Bibri (2020a) tailored it to the futures study with respect to the requirements of the future vision (Table 2).

\section{The time horizon in backcasting-oriented futures studies}

A typical time horizon used in many backcasting-oriented futures studies is 50 years. This time horizon is appealing because it is both realistic and far enough away to allow major changes and even disruptions in technologies and cultural norms and values. There also is a large body of work on backcasting that takes the perspective of 25-50 years as a time horizon. The futures study follows this perspective by covering the time period from 2020 to 2050, the time reasonably needed to develop the data-driven smart sustainable city as a desirable future. The rationale for this is that this new model of urbanism concerns particularly, but not only, those cities that are badging or regenerating themselves as sustainable, where, for example, some sustainable energy and waste systems, dense and diverse urban patterns, sustainable transportation infrastructure, green areas and parks, and technological infrastructure are already in place. And as they move towards 2050, a set of strategic pathways will be taken along the way to reach the optimal level of sustainability with the support of emerging and future ICT. And what this entails in terms of developing and implementing the IoT and big data technologies and their novel applications as well as establishing the associated technical and institutional competences on a citywide scale. Nonetheless, the futures study is not setting out a fixed time frame as the future is unknown and the world is uncertain, and the implication of this is that it can still take longer for sustainable cities to get closer to or reach the final destination. Not to mention those cities that are in the process of regenerating themselves as, or manifestly planning to become, sustainable and then smart sustainable. Worth pointing out is that the time horizon of 25-50 years associated with future visions as an evolutionary process is a basic principle to allow the policy and planning actions to pursue the path towards a more sustainable future.

Envisioning and attaining a transformational change which substantiates, extends, and also challenges the existing assumptions and claims made on sustainable cities as a problem of significant complexity, with a long time horizon to allow for making determined choices, is what backcasting entails as a strategic planning process and a problem-solving framework. In this regard, we identify signals of sustainable change 
Table 2 The guiding questions for each step in the backcasting-oriented futures study

The guiding questions for the backcasting study
Step 1: Detail strategic problem orientation (Part 1)
1. What is the model of urbanism to be studied?
2. What are the aim, purpose, and objectives of the backcasting study in
relation to this model?
3. What are the long-term targets declared by the goal-oriented backcasting
approach?
4. What are the objectives that these targets are translated to for backcasting
analysis?

Step 2: Detail strategic problem orientation (Part 2)

Methods and tools

Research design and problem formulation

1. What are the main prevailing trends and expected developments related to analysis the model to be studied?

2. What are the key sustainability problems associated with the current model of urbanism and what are the causes?

3. How is the problem defined?

\section{Step 3: Generate a sustainable future vision}

1. What are the demands for the future vision?

Creativity method and

2. How does the future model of urbanism look like?

visualization method

3. How is the future model of urbanism different from the current model of urbanism?

4. What is the rationale for developing the future model of urbanism?

5. Which sustainability problems have been solved and which technologies

have been used in the future vision?

\section{Step 4: Conduct empirical research}

1. What is the rationale for the methodological framework to be adopted?

2. Which category of case study design is most relevant to investigating the

dimensions of the future model of urbanism?

3. How many case studies are to be carried out and what kind of urban

phenomena should they illuminate?

4. To what extent can this investigation generate new ideas and illustrate the theories applied and their effects, as well as underpin and increase the feasibility of the future model of urbanism?

\section{Step 5: Specify and integrate the components of the future model of} urbanism

1. What urban and technological components are necessary for developing the future model of urbanism?

2. How can all these components be integrated into a framework for strategic sustainable urban development planning?

3. What are the benefits, potentials, and opportunities of the future model of urbanism?

\section{Step 6: Perform backwards-looking analyses}

1. What built infrastructure changes are necessary for achieving the future vision?

2. What urban infrastructure changes are necessary?

3. What ICT infrastructure changes are necessary?

4. What social infrastructure changes are necessary?

5. What institutional changes are necessary?

Source: Bibri (2020a)

and also determine short-term planning and policy goals that can facilitate the longterm outcomes of the needed transition towards sustainability. Backcasting is most relevant when the future is uncertain and our actions are likely to influence, inspire, or, ideally, create that future. Given that there is often greater uncertainty over what may happen in longer time frames, the future vision may usefully be described using principles and well-designed goals rather than specifics.

\section{Case study research}

Case study research has long had a prominent position in many disciplines and professional fields, established as a credible, valid design that facilitates the investigation and 
understanding of complex phenomena in their real-world settings. It has benefited from the prior development of the theoretical propositions contributed by a number of researchers with different backgrounds to this design. Similarly, the methodological development of case study research has emanated from the influence of the different researchers' perspectives and interpretations of this design. This has resulted in a pragmatic, flexible research approach, capable of providing an up-close, in-depth, and detailed examination of a wide range of specific cases and a comprehensive understanding of a large number and variety of issues. Therefore, case study research has grown in reputation as an effective research methodology. As a result, it has undergone substantial improvement through the application of a diversity of approaches. Central to this is the underpinning ontological and epistemological orientations of the numerous researchers involved in the evolution of case study research as coming from various disciplines. While over time the contributions of those researchers have helped to develop and strengthen case study research, the variety of disciplinary backgrounds has also added complexity, particularly around how such research is defined, described, and applied in practice. The nature of this complexity is explored in more detail by Farquhar (2012).

\section{Definitional issues}

There is a variety of definitions and descriptions of case study research presented across the literature, which has resulted from researchers with different philosophical perspectives. The proliferation of definitions can create confusion when attempting to understand case study research. The most common definitions come from the work of Yin (2014), Stake (1995), Merriam (2009), Thomas (2011), and Creswell et al. (2007). Yin's definition (2014) focuses on the scope, process, and methodological characteristics of case study research, emphasizing the nature of inquiry as being empirical, and the importance of context to the case. On the other hand, Stake (1995, p. xi) maintains a focus on what is studied (the case) rather than how it is studied (the method), describing case study research as "the study of the particularity and complexity of a single case, coming to understand its activity within important circumstances." Merriam (2009, p. 40) includes what is studied (the case) and the products of the research (the outcome) when defining case study as: "an in depth description and analysis of a bounded system". The author emphasizes the defining feature of case study research as being the object of the study (the bounded system; i.e., the case) adding that case study research focuses on a particular thing and that the product of an investigation should be descriptive and heuristic in nature. In taking the distinction between the subject of the study and the object of the study into account, Thomas (2011, p. 513) defines cases studies as "analyses of persons, events, decisions, periods, projects, policies, institutions, or other systems that are studied holistically by one or more methods. The case that is the subject of the inquiry will be an instance of a class of phenomena that pro-vides an analytical framean object-within which the study is conducted and which the case illuminates and explicates." Creswell et al. (2007) describe case study as a type of design in qualitative research, an object of study, and a product of the inquiry. The authors conclude with a definition that collates the hallmarks of the key approaches to 
case study and represents the core features of a case study: "a qualitative approach in which the investigator explores a bounded system (a case) ... over time through detailed, in-depth data collection involving multiple sources of information ... and reports a case description and case-based themes" (Creswell et al. 2007 , p. 245). In particular, the case study approach entails the use of multiple sources of evidence. The use of multiple methods to collect and analyze data are found to be mutually informative in the case study research where together they provide a more synergistic and comprehensive view of the problem under study (Flyvbjerg 2011; Merriam 2009; Stake 2006). All in all, the varied definitions stem from the researchers' differing approaches to developing case study methodology and often reflect the elements they emphasize as central to their designs. The diversity of the approaches to case study, which is addressed next, subsequently adds diversity to its definition and description (Flyvbjerg 2011).

In the framework of the futures study, the four case studies analyze a range of different elements within the boundaries of four cities and two districts. They examine contemporary real-world phenomena and seek to inform the theory and practice of data-driven smart sustainable cities of the future by illustrating what has worked well, what has been achieved, what is the current situation, what needs to be improved and transformed in the future, and how this can be done. They serve as a way to illustrate theories and the effects of their application in regard to urban living. They are additionally regarded useful for understanding how different elements fit together and (co-)produce the observed impacts in a particular context based on a given set of intertwined factors.

\section{The mixed use of terminology-methodology versus method}

One of the challenges to the understanding of case study research pertains to it being referred to as a methodology and a method. Mills (2014) distinguishes methodology as the lens through which the researcher views and makes the decision about the study, and method as a set of procedures and techniques employed in the study. Also, both quantitative and qualitative methods are used within the case study designs, which brings further obscurity to the question of methodology (Stake 1995; Stewart 2014; Yin 2014). Compounding this ambiguity is the terminology used in the literature, an approach, research design, qualitative design, research strategy, case study, qualitative case study, and/or a form of inquiry (e.g., Anthony and Jack 2009; Brown 2008; Creswell 2014; Merriam 2009; Simons 2009; Stake 1995; 2006; Stewart 2014; Yin 2014, 2017). These terms are used interchangeably without definitional clarity (see, e.g., Creswell 2014; Flyvbjerg 2011; Merriam 2009; Stake 1995, Stake 2006; Simons 2009; Stewart 2014; Yin 2014, 2017) This mixed use of terminology has generated a cacophony that has led to an exasperating confusion in case study research. This is due to the definitional separations between these terms, especially methodology and method, and the varied application of the case study in research endeavors (George and Bennett 2005). Therefore, the distinction between methodology and method accentuates the need for the researcher to describe the particular underpinning methodology adopted and to clarify the alignment of the chosen methods used with their philosophical assumptions and their chosen approach. In the context of the futures study, case study research 
emphasizes that an overarching methodology shapes a case study design and that multiple sources of data and methods are used (Merriam 2009; Stake 2006; Yin 2014).

\section{Design. purpose, and process}

Various designs have been proposed for preparing, planning, and conducting case study research. The philosophical underpinnings of the researchers that have contributed to the development of case study research have created a variety and diversity of approaches. Under the more generalized category of case study, there exist several categories, each of which is custom selected for use depending on the objectives of the researcher, including:

- Illustrative case studies-these are primarily descriptive studies. They typically utilize one or two instances of an event to show the existing situation. Illustrative case studies serve primarily to make the unfamiliar familiar and to give readers a common language about the topic in question

- Exploratory case studies-these are condensed case studies performed before implementing a large scale investigation. Their basic function is to help identify questions and select types of measurement prior to the main investigation. The primary pitfall of this type of study is that initial findings may seem convincing enough to be released prematurely as conclusions.

- Cumulative case studies-these serve to aggregate information from several sites collected at different times. The idea behind these studies is that the collection of past studies will allow for greater generalization without additional cost or time being expended on new, possibly repetitive studies.

- Critical instance case studies-these examine one or more sites either for the purpose of examining a situation of unique interest with little to no interest in generalization, or to call into question a highly generalized or universal assertion. This method is useful for answering cause and effect questions.

The methodological discourse stresses a number of themes on the direction and organization of case studies-their design. Thomas (2011) summarizes some of the better-known analyses in Table 3.

For an explication of the general themes raised in Table 3, the interested reader can be directed to the analysis from George and Bennett (2005). This especially useful analysis draws heavily on the widely used typologies of Lijphart (1971) and, principally, Eckstein (1975). George and Bennett (2005) emerge with six types of case study, namely:

1. Atheoretical (or configurative idiographic) case studies-the goal is to describe a case very well, but not to contribute to a theory;

2. Interpretative (or disciplined configurative) case studies-the goal is to use established theories to explain a specific case;

3. Hypothesis-generating (or heuristic) case studies - the goal is to inductively identify new variables, hypotheses, causal mechanisms, and causal paths. Outlier cases may be especially valuable; 
4. Theory testing case studies - the goal is to assess the validity and scope conditions of single or competing theories;

5. Plausibility probes preliminary studies - the goal is to assess the plausibility of new hypotheses and theories, or to determine whether further study is warranted; and

6. Building block studies of particular types or subtypes of a phenomenon-the goal is to identify common patterns across cases or serve a particular kind of heuristic purpose

Notwithstanding the commonalities and differences of these types of case studies, the key feature emerged from this list is that there is a mixture of criteria for classification. However, while case study research has evolved to be a pragmatic, flexible research approach, the variation in application, validity, and purposefulness can create a confusing platform for its use (Anthony and Jack 2009). Nevertheless, the versatility of case study research to accommodate the researcher's philosophical position presents a unique platform for a range of studies that can generate greater insights into different areas of inquiry. With the capacity to tailor approaches, case study designs can address a wide range of questions that ask why, what, and how of an issue and assist researchers to explore, explain, describe, evaluate, and theorize about complex issues in context. This relates to the decisions that need to be made about the purpose, approach, and process in the case study. Thomas (2011) proposes a typology for the case study wherein purposes are first identified (evaluative, exploratory, or descriptive), then approaches are delineated (theory-testing, theory-building, or illustrative), then processes are decided upon, with a principal choice being between whether the study is to be single or multiple, and choices also about whether the study is to be retrospective, snapshot, or diachronic, and whether it is nested, parallel, or sequential.

Following this typology, the purpose in the four case studies is descriptive, the approach is illustrative, and the process is multiple. The purpose is about the reason of doing these studies. The approach is about the broad objects of these studies. The process is bout the operational processes of these studies, which entails returning to the six subjects (as distinct from the four objects) and to the boundary decisions made at the outset. There has to be an examination of the nature of the decisions that were made at that time about the parameters that delimit the subject of the study (Thomas 2011). In this context, these parameters fall around the locus of defining the four cases by more of a range of boundary considerations: a range of different elements that were studied in their complexity. This

Table 3 Kinds of case studies as enumerated by different analysts

\begin{tabular}{lllll}
\hline Meriam (1988) & Stake (1995) & Bassy (1999) & de Vaus (2001) & Yin (2009) \\
\hline Descriptive & Intrinsic & Theory seeking & Descriptive/explanatory & Critical \\
Interpretative & Instrumental & Theory testing & Theory testing/building & Extreme/unique \\
Evaluative & Single/collective & Storytelling & Single/multiple case & Longitudinal \\
- & - & Picture drawing & Holistic/embedded & Representative \\
- & - & Evaluative & Parallel/sequential & Revelatory \\
- & & - & Retrospective/prospective & - \\
\hline
\end{tabular}

Source: Adapted from Thomas (2011) 
determines the process of the four case studies, and this is about the presence of the comparative element to these studies as multiple ones (Stake 2005). As stated in this regard by Thomas (2011, p. ): "the case study, while it is of the singular, may contain more than one element in its subject and if this is so-that is, if there are two or several cases-each individual case is less important in itself than the comparison that each offers with the others." The key focus in the four case studies is not on the nature and shape of relationships per se in one city but rather on, to some extent, the nature of the difference between the one and the other and what this informs us about the dynamics that are significant in this difference. This comparative element is why Schwandt (2001) calls this kind of case study cross-case analysis. For the four case studies, we considered additional features of the situation. How could the different studies be used for comparison-for crosscase analysis in Schwandt's (2001) terms? The principal means of doing this was by straightforward comparison between clearly different examples. Moreover, the four studies were parallel in the sense that the two cases in each of them were happening and studied concurrently.

To elaborate further on the purpose, descriptive case study accentuates the flexibility of case study research as a distinct form of inquiry that enables detailed and in-depth insights into a diverse range of issues across a number of disciplines. There is a consensus that the focus of a case study is the detailed inquiry of a unit of analysis as a bounded system (the case), over time, within its context. In descriptive case study research, questions and propositions about the four phenomena of compact cities, ecocities, data-driven smart cities, and environmentally data-driven smart sustainable cities are carefully scrutinized and articulated at the outset. The articulation of what is known about these phenomena is referred to as a descriptive theory. Therefore, the main purpose of the four case studies is to describe the selected cases in detail and in depth based on that articulation, and in their real-world settings. It is worth pointing out that internal validity in research design is not relevant as in most descriptive studies. Internal validity denotes the approximate truth about inferences regarding cause-effect, or the extent to which a study establishes a trustworthy cause-and-effect relationship between a treatment and an outcome. Accordingly, it is relevant in studies that attempt to establish a causal relationship such as explanatory and hypothesis-generating (or heuristic) case studies, whereas descriptive research is used to describe some characteristics of certain phenomena, and does not address questions about why and when these characteristics occurred-no causal relationship.

\section{Descriptive case study steps}

Descriptive case study research, as defined by (Yin 1984, 2009), has been identified as the most suitable methodology for the four case studies. This methodology has been chosen considering the nature of the problems being investigated, the research aim, and the present state of knowledge with respect to the topics on focus. It involves the description, analysis, and interpretation of the present nature, composition, and processes of the six cities selected, where the focus is on the prevailing conditions. That is, how these cities behave in terms of what has been realized and the ongoing implementation of plans based on the corresponding practices and strategies depending on the 
topic of each of the four case studies. To obtain a broad and detailed form of knowledge in this regard, we adopted a process that consists of five steps tailored to each of the four case studies conducted (see Table 4):

Based on Table 4, the outcomes of descriptive case study can lead to an in-depth understanding of such aspects as behaviors, processes, practices, and relationships in context with respect to different phenomena.

\section{Selection criteria}

There are different strategics for selecting the cases to be investigated. Seawright and Gerring (2014) list seven case selection strategies:

1. Typical cases-exemplify a stable cross-case relationship. These cases are representative of the larger population of cases, and the purpose of the study is to look within the case rather than compare it with other cases

2. Diverse cases-have variation on the relevant $\mathrm{X}$ and $\mathrm{Y}$ variables. Due to the range of variation on the relevant variables, these cases are representative of the full population of cases.

3. Extreme cases-have an extreme value on the $\mathrm{X}$ or $\mathrm{Y}$ variable relative to other cases

4. Deviant cases-defy existing theories and common sense. They not only have extreme values on $\mathrm{X}$ or $\mathrm{Y}$ (like extreme cases), but defy existing knowledge about causal relations

5. Influential cases-are central to a model or theory

6. Most similar cases-are similar on all the independent variables, except the one of interest to the researcher

7. Most different cases-are different on all the independent variables, except the one of interest to the researcher

The strategy pursued in the four case studies is influential cases. In addition, the selection of the six cases investigated was done in line with the overall aim of the futures study, with a focus on the leading cities from the ecologically and technologically advanced European countries with respect to urban planning and development. The subjects have come into focus because of the inherent interest of the six cases-they are key cases of the phenomena of compact cities, ecological cities, data-driven smart cities, and environmentally data-driven smart sustainable cities.

However, the subjects identified are in no sense a sample, representative of a wider population. Rather, they are selected because they are interesting examples through which the lineaments of the four objects: (1) compact urbanism, (2) ecological urbanism, (3) data-driven smart urbanism, (4) and environmentally data-driven smart sustainable urbanism can be refracted. Their scope is not restricted (e.g., Thomas 2011; White 1992).

\section{Compact cities: Gothenburg and Helsingborg}

The cases of Gothenburg and Helsingborg have been selected using a theoretical sampling approach (Yin 1984). The two cities fall within the category of large cities in Sweden: 
Table 4 Descriptive case study steps for the four case studies conducted

\section{Compact City}

- Using a narrative framework that focuses on the compact city model and its contribution to the three goals of sustainability as a real-world problem and that provides essential facts about it, including relevant background information

- Introducing the reader to key concepts, strategies, practices, and policies relevant to the problem under investigation

- Discussing benefits, conflicts, and contentions relevant to the problem under investigation

- Explaining the actual solutions in terms of plans, the processes of implementing them, and the expected outcomes.

- Offering an analysis and evaluation of the chosen solutions and related issues, including strengths, weaknesses, tradeoffs, and lessons learned.

\section{Eco-City}

- Using a narrative framework that focuses on the eco-city as a real-world problem and provides essential facts about it, including relevant background information

- Introducing the reader to key concepts, models, and design strategies relevant to the problem under investigation

- Discussing benefits and research gaps and issues relevant to the problem under investigation

- Explaining the actual solutions in terms of plans, the processes of implementing them, and the expected outcomes

- Offering an analysis and evaluation of the chosen solutions and related issues, including strengths, weaknesses, tradeoffs, and lessons learned.

\section{Data-Driven Smart City}

- Using a narrative framework that focuses on the data-driven smart city as a real-world problem and provides essential facts about it, including relevant background information

- Introducing the reader to key concepts, technologies, and data-driven smart sustainable urbanism processes and practices relevant to the problem under investigation

- Providing an overview of the literature review previously conducted in relation to the study, which delivers a comprehensive, state-of-the-art review on the sustainability and unsustainability of smart cities in relation to big data technology, analytics, and application in terms of the underlying foundations and assumptions, research problems and debates, opportunities and benefits, technological developments, emerging trends, future practices, and challenges and open issues

- Explaining the actual solutions in terms of plans, the processes of implementing them, and the expected outcomes

- Offering an analysis and evaluation of the chosen solutions and related issues, including strengths, weaknesses, tradeoffs, and lessons learned.

\section{Environmentally Data-Driven Smart Sustainable City}

- Using a narrative framework that focuses on data-driven smart solutions and their role and potential in improving and advancing environmental sustainability in the framework of the smart sustainable city as a realworld problem, and provides essential facts about it, including relevant background information.

- Introducing the reader to key concepts, core enabling technologies, infrastructures, landscapes, frameworks, as well as urban operating systems and urban operations centers, all with relevance to the problem under study.

- Identifying the commonalities and differences between the two cities with respect to the emerging technologies

- Explaining the actual solutions in terms of plans and visions, the processes of implementing them, and the realized and expected outcomes

- Offering an analysis and evaluation of the relevant solutions and related issues, including strengths, weaknesses, and lessons learned.

Gothenburg is the second-largest city in Sweden, after the capital Stockholm, fifthlargest in the Nordic countries. It is located by Kattegat, on the West coast and in the south-west of Sweden. The area of Gothenburg has an approximate size of $447.8 \mathrm{~km}^{2}$. Gothenburg has a population of approximately 599,000 in the city center and about 1 million inhabitants in the metropolitan area. It is home to many students from all over the world, as there are two universities in the city: the University of Gothenburg and Chalmers University of Technology. It is in a phase of expansion with a growing population and as a result of increased immigration. The crisis during the 1970s has drastically transformed Gothenburg, from an industrial city to a knowledge and event city, 
where the two universities have become very important, and the focus on the sustainable development has increased.

Helsingborg is located in the Öresund region, exactly where the Øresund straits are narrowest. The area of Helsingborg has an approximate size of $346 \mathrm{~km}^{2}$, Around 3.9 million people live and work in this region. Approximately 135,300 people live in Helsingborg. Thanks to its position, Helsingborg is a strategic hub, close to Malmö and Copenhagen. It is a regional center situated within the larger metropolitan regions of Malmö and Copenhagen. It is a former industrial city that has made an effort to regenerate old industrial sites in response to the need for enhanced economic growth in order to contribute to new commercial and cultural activities and to create new urban residential areas while keeping its industrial heritage intact.

In addition, the ambition and success of these cities in the field of compact urbanism makes their planning practices and development strategies an ideal sample to analyze. This assertion can be demonstrated considering the international positioning of Sweden in urban sustainability. Sweden is one of the leading Scandinavian, European, and Global countries that have exemplary practical initiatives in sustainable cities, both compact cities and eco-cities, in addition to a number of recent endeavors related to smart sustainable cities. According to several rankings, Sweden, Denmark, Finland, Norway, Germany, the Netherlands, and Japan have the highest level of sustainable development practices (Dryzek 2005). Another ranking has recently been reported based on 2018 Environment Performance Index (EPI) data: Sweden is one of the world's leading countries in sustainability and has an overall score of 80.51 in regard to environmental friendliness (Buder 2019). In fact, several empirical studies identify from the mid-1980s onward an increasing ecological disruption in most of the ecologically advanced nations, such as Sweden, Denmark, Germany, and the Netherlands (Mol 2000). Sweden and the rest of the Nordic countries have a comparatively low impact in terms of CO2 emissions (The Norden 2008).

The two cities selected have been receptive to the compact city ideal. They have chosen the compact city model as the most effective planning system that can go hand in hand with sustainable development in light of the relevance and usefulness of the findings produced by many studies in the field of sustainable urbanism. As such, they may be seen as successful examples of compact city planning and development, and critical cases in sustainable urban development. This is due to their long planning traditions and the existence of relatively solid economic resources on the local level, the national focus on sustainability in Sweden, and the wide authorization given to the local authorities (Baldersheim and Ståhlberg 2002; Kalbro et al. 2010; Rose and Ståhlberg 2005). Moreover, they express sustainability ambitions in their master and comprehensive plans, support progress and expansion over time, and experience developmental pressure on their landscapes due to rapid urban growth. Additionally, it was important to ensure that there was sufficient information available in the public realm to carry out the analysis of the two cases. All in all, the selection criteria secured cases where sustainability discourses, planning measures, practical advances, and future goals are present. Gothenburg and Helsingborg illustrate how ambitious cities handle the challenges of sustainability and urbanization, and how different values and interests are weighted and secured through urban planning and development. 


\section{Eco-cities: Stockholm and Malmö}

The cases of Stockholm and Malmö and Helsingborg have been selected using a theoretical sampling approach (Yin 1984). The two cities fall within the category of large cities in Sweden:

Centrally located in the growing Baltic region, Stockholm is the largest city in Sweden, the capital of Sweden, and the most populous urban area in Scandinavia. Approximately 1.633 million habitants live in the urban area, 2.4 million in the metropolitan area, and 965,232 in the municipality. Moreover, Stockholm is an important global city and one of the world's cleanest capitals and metropolises due to the absence of heavy industry and fossil fuel power plants. Indeed, it has a long history of environmental work and was the first city to be granted the European Union's Green Capital award by the European Commission in 2010 due to its high environmental standards and ambitious goals for further environmental improvement (European Green Capital 2009). This includes climate change, air quality, green energy, waste and water management, wastewater treatment, sustainable land use, environmental management, and sustainable transport. The city has a long-term commitment to sustainable development and the environment. Stockholm and SRS received an award for best sustainable urban development project in the category Sustainable Communities, which was presented at the UN Climate Change Conference in Paris 2015 by the C40 Cities Climate Leadership Group, a network connecting more than 80 of the world's megacities (Stockholm City 2020). The award is proof that Stockholm is an international leader in sustainable urban development.

Malmö is the largest city of the Swedish County of Skåne and the third-largest city in Sweden, after Stockholm and Gothenburg, with a population of 316,588 inhabitants out of a municipal total of 338,230 in 2018. Being perfectly situated along the straights, it separates Sweden from Denmark, and also connects Sweden to Denmark through the Öresund bridge, whose opening in 2000 made Malmö Sweden's principal point of entry. Since the construction of the Öresund Bridge, Malmö has undergone a major transformation which can be seen more clearly in Western Harbor (Västra Hamnen) than in any other part of Malmö. The Municipality of Malmö had initially invested in residential development on the site by means of a European housing exhibition focused on sustainability-Bo01, exploring a drastic vision of future living intended to provoke discussion and to be a best practice exemplar pilot project for a mixed district. This event was held in Malmö in 2001.

Another rationale for selecting these cities is that, in addition to what Sweden is renowned for as mentioned earlier, they have long been receptive to the eco-city ideal as well as engaged in ecological planning for almost two decades (Bibri and Krogstie 2020a). Malmö is the second largest city in Sweden's fastest growing urban landscapes after Stockholm and one of the Sweden's most ambitious cities in terms of sustainable planning. This is well demonstrated by the great deal of planning material and ideas produced about sustainable cities, for which the city has indeed been internationally acclaimed and awarded as notably:

- The Liveable community's award 2007

- Sweden's first Fairtrade City 2006 and 2012

- The fourth greenest city in the world by Grist in 2007

- One of the first creative city in Europe by Fast Company 2009 
- The World Green Building Council's BEX Award 2009

- Sweden's most climate-smart Municipality 2011

- Environment Municipality of the Year 2010, 2013, and 2014

- European Green Capital Finalist 2012 and 2013

- Top 3 greenest cities in the world 2013

- The fourth Sustainable Urban Mobility Planning (SUMP) Award 2015

The two cities have chosen the eco-city strategy as the most effective planning system that can go hand in hand with sustainable development in light of the relevance and usefulness of the findings produced by many studies in the field of ecological urbanism. Particularly, Stockholm Royal Seaport (SRS) and Western Harbor in Malmö have been selected as eco-city districts for investigation. In recent years, much of the environmental work within Stockholm has focused on developing new sustainable urban districts. One recent initiative is the SRS district, whose vision is to become a "world class environmental city district" (Stockholm City 2010). SRS is an area of 236 ha that is being transformed from a brownfield zone into a site of 12,000 homes, 35,000 workplaces, $600,000 \mathrm{~m} 2$ of commercial spaces, and parks and green spaces, with approximately 35,000 people to live and/or work in the area. It is designated as an environmental profile area with the mandate to become a model of sustainable urban development (Stockholm City 2020). It is among the key climate-positive projects in the world that are considered as examples of successful environmental and economic urban developments, demonstrating that cities can reduce carbon emissions and grow in climate friendly ways. The vision of SRS relates to the overall goal established by the City of Stockholm to be fossil fuel-free by 2050 (Stockholm City 2009, 2018). In this respect, SRS environmental profile should consolidate Stockholm's position as a leading capital in climate work, support the marketing of Swedish environmental technology, and contribute to the development of new technologies (Bibri 2020a, b).

With respect to Western Harbor, it is designated as an environmental profile area with the mandate to become a model of modern eco-city district. Its aim is to become an international leading example of an environmentally sound, densely populated district. Bo01 represents the first step in the process of transforming the 160 ha of Western Harbor area into a sustainable urban district. When completed, the Western Harbor area will consist of a total of approximately 11,000 homes and 17,000 jobs, and over 20,000 people will be able to live in the area (Malmö City 2015). At the beginning of 2014, this district had approximately 4000 homes and approximately 10,000 jobs, in addition to a number of facilities and services (Malmö City 2015). The original plan created to redevelop this formerly industrial, waterfront real estate has led to the transformation of 18 ha into a mixed-use residential community built according to sustainable principles. The development of Bo01 in 2001 was to accommodate commercial and social uses, and related housing exhibition in 2002 showcased what was achievable in terms of planning, designing, and building to the highest energy efficiency and renewable energy standards. This in turn enabled the testing of new sustainable technologies and approaches to their application on a wider scale. However, the key goal of Western Harbor is to become an environmentally sound and sustainable urban district, integrating all three dimensions of sustainability, ecological, economic, and social (Malmö City 2015). 
SRS and Western Harbor illustrate how ambitious districts handle the environmental and sustainability challenges, and how different values and interests are weighted and secured through urban planning and development. As such, they may be seen as successful examples of ecological urbanism, as well as critical cases in sustainable urban development. Moreover, Stockholm and Malmö express environmental and sustainability ambitions in their master and comprehensive plans, support progress and expansion over time, and experience developmental pressure on their landscapes due to urbanization (Bibri and Krogstie 2020a).

\section{Data-driven smart cities: Barcelona and London}

The cases of Barcelona and London have been selected using a theoretical sampling approach (Yin 1984). The two cities fall within the category of large cities in Europe:

Barcelona is located in the northeast of Spain on the Mediterranean coast. It is the capital and largest city of the autonomous community of Catalonia, as well as the second most populous municipality of Spain. The area of Barcelona has an approximate size of $101.9 \mathrm{~km}^{2}$ and a population of 5.586 million habitants. With a population of 1.6 million within city limits, its urban area extends to numerous neighboring municipalities within the Province of Barcelona and is home to around 4.8 million people, making it the fifth most populous urban area in the European Union after Paris, the Ruhr area, Madrid, and Milan. It is one of the largest metropolises on the Mediterranean Sea, located on the coast between the mouths of the rivers Llobregat and Besòs, and bounded to the west.

London is the capital and largest city of England and the United Kingdom. The city stands on the River Thames in the south-east of England, at the head of its 50-mile (80 $\mathrm{km}$ ) estuary leading to the North Sea. The area of London has an approximate size of $1572 \mathrm{~km}^{2}$ and a population of 8.982 million habitants. London is considered to be one of the world's most important global cities. London's universities form the largest concentration of higher education institutes in Europe, and London is home to highly ranked institutions.

Selecting Barcelona and London amongst all the top cities leading the smart city ranking (e.g., Eden Strategy Institute 2018) and the data-driven city ranking (Bibri and Krogstie 2020b; Nikitin et al. 2016) in the world is justified by three key reasons. First, the focus of the futures study is on the European Cities of which London and Barcelona are the leading data-driven smart cities. Second, both cities are widely recognized and mostly reputed for using applied data-driven technology solutions in their operational functioning and planning as part of the city management, and what this entails in terms of infrastructure, competencies, data sources, and data-oriented institutional competences (e.g., Bibri 2020a; Batty 2013; Eden Strategy Institute 2018; Kitchin 2014; Kitchin 2016; Nikitin et al. 2016; Noori et al. 2020; Sinaeepourfard et al. 2016). Third, they are increasingly seen as the leading European cities that are taking the initiative to use and apply the IoT and big data technologies to advance sustainability-thereby evolving into what has been termed as data-driven sustainable smart cities. The local governments of Barcelona and London have established a number of projects and implemented several planning measures for modernizing their ICT infrastructure and strengthening their readiness to integrate data-driven technology solutions into urban processes and practices. 
In view of the above, the two cities demonstrate exemplary practical initiatives as regards the integration of data-driven solutions and sustainable development strategies. As such, they may be seen as successful examples of the emerging paradigm of smart urbanism, as well as critical cases in sustainable development within the technologically advanced nations. On the whole, the selection criteria secured cases where advancements in the IoT and big data technologies and their novel applications for sustainability, coupled with future visions in this regard, are present.

\section{Environmentally data-driven smart sustainable cities: Stockholm and Barcelona}

The cases of Stockholm and Barcelona have been selected using a theoretical sampling approach (Yin 1984, 2009). The Cities of Stockholm and Barcelona fall within the category of large cities in Europe. The area of Stockholm has an approximate size of 188 $\mathrm{km}$ and a population of 1,632,798 million habitants, and the area of Barcelona has an approximate size of $101.9 \mathrm{~km}^{2}$ and a population of 5.586 million habitants. Additionally, the success of the two cities in the field of sustainable urbanism and smart urbanism, respectively, makes their strategies and solutions an ideal sample to analyze. This assertion can be easily demonstrated considering the multiple awards the two cities have received during recent years and their international positioning. This pertains to Stockholm as both a sustainable city and a smart sustainable city (e.g., Akande et al. 2018; Bibri 2020a, b; European Green Capital 2009; Holmstedt et al. 2017; Kramers et al. 2016; Stockholm City 2009, Stockholm City 2010, Stockholm City 2018, Stockholm City 2020). Stockholm is at the forefront of ecological/environmental thinking. It has very strong environmental policies and is focused on improving the quality of life of its citizens (Lindström and Eriksson 1993; Stockholm City 2018) with support of advanced technologies (Bibri 2020a; Wouter et al. 2018). According to the City of Stockholm, an IoT-based infrastructure is highly important for, and the backbone for building, smart sustainable cities nowadays (Bibri and Krogstie 2020a). As stated by Johansson (2018), a project leader, the reason for establishing the IoT infrastructure in the city "is because we have a lot of challenges. We know that using the smart technologies can help us to be a better city, for the people that live there, work there and even the people that are visiting us." He also stated that the environmental department in the city is active with smart technologies. During the period 2015-2016, an ICT network was established in the City of Stockholm to find a more comprehensive way of using ICT, and the digital development department of the city was established with a much broader take on ICT (Kramers et al. 2016). The city has recently taken concrete actions for using datadriven technologies to reach its environmental targets by 2040, in particular in relation to the initiative of SRS (Bibri and Krogstie 2020a). This smart eco-city district starts with a common vision in smart planning on the basis of the IoT technology (The Nordics 2017).

The international positioning pertains to Barcelona as a smart city (e.g., Achaerandio et al. 2011; Ajuntament de Barcelona 2014a; Cohen 2012a, b, 2014; European Commission 2014; Eden Strategy Institute 2018; Manville et al. 2014; Nikitin et al. 2016) and a sustainable smart city (e.g., Bibri and Krogstie 2020b; Noori et al. 2020). Indeed, Barcelona is taking concrete actions for implementing the applied data-driven technology solutions developed for urban operational functioning and planning as part of the city management to improve and advance sustainability-thereby evolving into what has been termed as a data-driven 
sustainable smart city (Bibri 2020a). Barcelona is strongly committed to becoming a smart city and a show-case for the rest of the world in sustainable urban development (Mora and Bolici 2016). This is clearly figured in the public statements proposed by different local government representatives (see, e.g., Ajuntament de Barcelona 2011, 2012, 2013, 2014b, 2014c). One of the strategies of the Municipal Action Program is called "urban renewal" and is associated with a precise strategic commitment to transform "Barcelona into a sustainable, smart urban model at the service of its residents" (Mora and Bolici 2016, p. 3).

In light of the above, the two cities demonstrate exemplary practical initiatives as regards the integration of data-driven solutions and sustainable development strategies. As such, they may be seen as successful examples of the environmentally data-driven smart sustainable city, as well as critical cases in environmental sustainability. This is further due to the national focus on environmental sustainability in Stockholm and the national focus on ICT in Barcelona, with visible shared goals and visions in regard to these foci. All in all, the selection secured cases where advances in the IoT and big data technologies and their novel applications for environmental sustainability, coupled with future visions and goals, are present.

\section{Subject, object, unit of analysis, and data collection method}

Whatever the frame of reference for the choice of the subject of the case study, there is a distinction to be made between the subject and the object of the case study. The subject is the "practical, historical unity" through which the theoretical focus of the study is being viewed (Wieviorka 1992), and the object is the analytical frame within which the study is conducted and which the case illuminates (Thomas 2011). Compact urbanism, ecological urbanism, data-driven smart urbanism, and environmentally data-driven smart sustainable urbanism were identified as the universe-that is, the class of events-of which a group of two cases in each of the four case studies represent instances. The subjects of the four case studies, which are the six cases themselves, are thus the instances of these four urban phenomena, and the latter-the phenomenacomprise the analytical frame. This is based on the typology proposed by Thomas (2011) for the case study following a definition wherein various layers of classificatory principle are disaggregated (Fig. 2).

For a "case" to exist, we must be able to identify a characteristic unit ... This unit must be observed, but it has no meaning in itself. It is significant only if an observer ... can refer it to an analytical category or theory. It does not suffice to observe a social phenomenon, historical event, or set of behaviors in order to declare them to be "cases." If you want to talk about a "case," you also need the means of interpreting it or placing it in a context (Wieviorka 1992, p. 160).

The aim of the futures study constitutes the basis for determining the unit of analysis concerning the four case studies. The objects of the four case studies have key differences as well as some overlaps, so do the units of the analyses. The new model of urbanism that the futures study is concerned with represents the amalgamation of the leading paradigms of urbanism. As to the first case study, the unit of analysis, the entity that frames what can be analyzed, is the design strategies of the compact city and the extent to which they support and balance the environmental, economic, and social goals of sustainability. Concerning the second case study, the unit of analysis is the 
strategies and solutions of the eco-city and the extent to which they integrate the environmental, economic, and social goals of sustainability. As regards the third case study, the unit of analysis is the applied solutions of the emerging data-driven smart city for sustainability. With respect to the fourth case study, the unit of analysis is the datadriven solutions applied in the sustainable city and the smart city for environmental sustainability.

The unit of analysis is essential to focalizing, framing, and managing the data collection and analysis. The qualitative data were extracted from multiple sources of evidence identified with a series of searches performed in various online databases. The relevant archive records and documents produced by public and private organizations were considered as primary sources (i.e., master plans, comprehensive plans, visions, strategies, agendas, project descriptions, presentations, etc.). In addition, a wealth of data was acquired from other documents produced by organizations or researchers not directly involved in the four initiatives of the city cases. These sources were considered as secondary (i.e., reports, newspaper articles, journal and online articles, conference proceedings, research project deliverables, etc.).

Another supporting form of the primary data used in regard to the first case study was face-to-face and telephone interviews conducted with a total of 10 interviewees, including planners, architects, developers, consultants, and administrative servants, These interviewees were mostly involved in those areas associated with the challenging and conflicting issues of the compact city initiatives. These issues were identified based on the previous empirical studies carried out in relevance to the compact city model, as well as on the arguments advanced by the critics of this model in the literature. One of the key objectives of the interviews was to corroborate any progress made by the two cases investigated as to the development and implementation of new measures to address the common environmental and social issues of the compact city.

As regards the second case study, the other supported form of the primary data was face-to-face and telephone interviews with a total of 10 interviewees, including planners, architects, developers, project leaders, and administrative servants. They were selected from the ongoing projects of SRS and Western Harbor, especially those working within the areas that involve contentious and challenging issues based on both the outcome of the previous empirical studies carried out in relevance to the eco-city model, as well as the arguments advanced by the critics of this model in the literature. One of the key objectives of the interviews was to corroborate the progress made by the

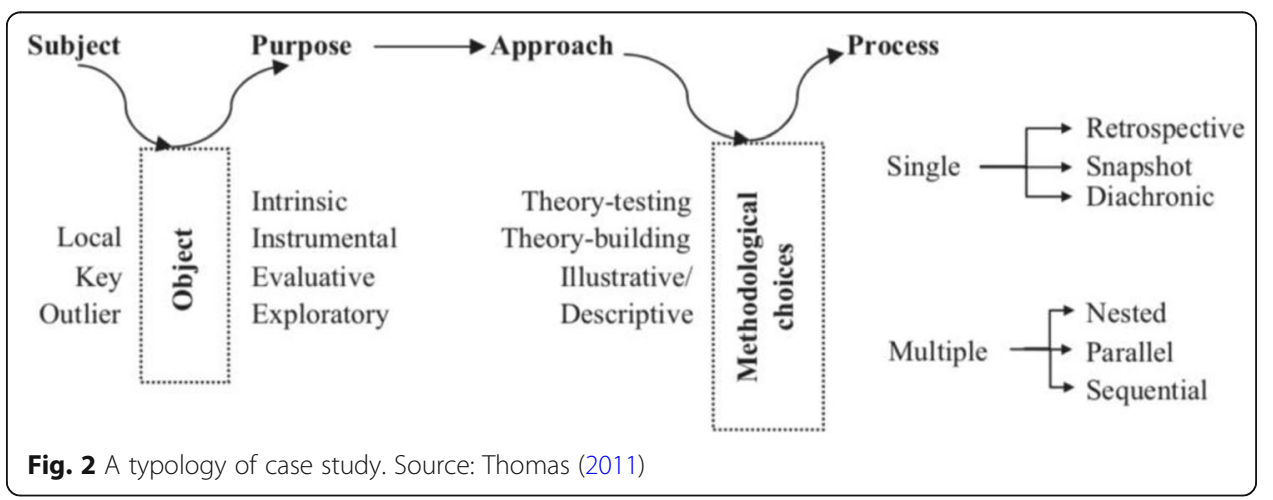


Municipalities of Stockholm and Malmö as to the development and implementation of new measures to address the issues related to the economic and social dimensions of sustainability. As regards the environmental dimension of sustainability, the objective of the interviews was to document the practical advances claimed to be made in the field of sustainable urban development, as well as the extent to which the eco-city district strategies have been implemented according to the plan.

The interviews were mostly unstructured. They were intended to be used in ways that can be adapted to the interviewees' roles and interests. This means that the interviewees were asked different questions. The findings were reported in a form of complementing, substantiating, and conflicting statements. Additionally, a set of face-toface and telephone conversations were conducted with some researchers and scholars at Lund University and Gothenburg University in relation to the first case study, and Stockholm and Malmö in relation to the second case study. Within the framework of the compact city, they were particularly important in providing further insights into some ongoing projects for strengthening the influence of the environmental and social goals of sustainability over urban planning and development practices in the ambit of sustainable cities. In terms of the eco-city, they provided insights into some ongoing projects and useful knowledge regarding the core dimension of environmental sustainability and the efforts being made to support the balancing of the three goals of sustainability through new endeavors focusing on social and economic issues in response to the agenda of sustainable development. As far as the face-to-face conversations are concerned, they took place with no schedule set in advance, whenever the circumstances allowed.

\section{Analytical method: thematic analysis}

To identify, analyze, interpret, and report the case-based themes, a thematic analysis approach was designed and employed. This qualitative analytical approach was deemed suitable given the form of knowledge and insights that we sought to gain from the qualitative data gathered in connection with the cases studies. Generally, it is up to the researcher to decide if this analytical approach is suitable for their research design, and whether it can be adapted for their own uses or purposes.

Thematic analysis is particularly, albeit not exclusively, associated with the analysis of textual material. It emphasizes identifying, analyzing, interpreting, and reporting themes, i.e., important patterns of meaning within the qualitative data that can be used to address the research problem. Braun and Clarke (2006) suggest that thematic analysis is flexible in terms of research design given that it is not dependent on any particular theory: multiple theories can be applied to this process across a variety of epistemologies. Also, thematic analysis is more appropriate when dealing with a large body of qualitative data. In addition to providing a flexible way of data analysis, thematic analysis permits researchers with different methodological backgrounds to engage in such type of analysis (Braun and Clarke 2006). However, this flexibility can lead to inconsistency and a lack of coherence when developing themes derived from the research data (Holloway and Todres 2003). Moreover, thematic analysis minimally organizes and describes qualitative data in detail, involves the risk of missing nuances in the data when used in a theoretical vacuum, does not allow researchers to make technical claims about language usage (Braun and Clarke 2006), and relies on the researchers' 
judgement. The latter relates to the issue of reliability due to the numerous potential ways of data interpretations and the potential for researcher subjectivity to distort the analysis. There is no one accurate interpretation of data, interpretations reflect the positioning of the researchers. Therefore, it is important for them to reflect carefully on their own interpretations and continually on how they are shaping the evolving analysis by paying close attention to the data to achieve a quality analysis. Thematic analysis takes as its analytic object meaning by attending to the content of text in its various forms, while keeping in mind how the data are generated, attending to some form of context for interpretation purposes. This pertains particularly to secondary data. Secondary analysis usually involves some degree of distance from the original data as regards to the research questions and place where the data were gathered (see Elliott et al. 2013 for a discussion).

Thematic analysis has proliferated so that it can be diverse. Hence, it is best thought of as an umbrella term for a variety of different approaches, which are underpinned by different philosophical assumptions as well as divergent in regard to procedures. Braun and Clarke (2006) distinguish between three main types of thematic analysis: coding reliability approaches, code book approaches, and reflexive approaches. Another classification entails inductive and deductive types of thematic analysis. The inductive approach involves allowing the data to determine the set of themes to be identified, and the deductive approach involves handling the data with some preconceived themes that are expected to be reflected in the data based on existing knowledge (descriptive theory). The latter is applied in the case studies carried out on compact cities and ecocities. With respect to the former, it is applied in the case studies performed on datadriven smart cities and environmentally data-driven smart sustainable cities. This is justified by the fact that these two approaches to urbanism are an emerging area of research and practice. That is to say, there is no established theoretical framework that gives a strong idea of what kind of themes to expect to find in the data (deductive). Indeed, the intent is to develop a framework based on what can be discovered as themes (inductive). Accordingly, these themes are not predetermined following the inductive approach. As an inductive analytical approach, thematic analysis can be used to address the different types of questions posed by researchers to produce complex conceptual cross-examinations of meaning in the qualitative data. In addition, this approach to thematic analysis is appropriate when analyzing and synthesizing a large body of datain the form of empirical studies, exploratory studies, conceptual frameworks, descriptive accounts, reviews, and so on. It has also been applied to produce theory-driven analyses. All in all, the researchers use thematic analysis as a means to gain insights and knowledge from the qualitative data gathered.

The main four steps of the analytical approach applied in the four case studies, with some slight differences, are as follows:

1. Reviewing the multiple sources of the data related to the selected cases. The outcomes of this process are numerous themes that are associated with the four models of urbanism in question. It is important to have a comprehensive understanding of the content of the planning documents and multidisciplinary literature, as well as to be familiarized with all aspects of the data collected. This step provides the foundation for the subsequent analysis. 
2. Pattern recognition (searching for themes) entails the ability to see patterns in seemingly random information. The aim is to note major patterns within the result of the first step. The second step looks for similarities within the sample and codes the results by concepts. Coding involves identifying passages of text that are linked by a common theme allowing to index the text into categories and therefore establish a framework of thematic ideas about it. In this step, the preliminary codes identified are the features of data that appear meaningful and interesting, and the relevant data extracts are sorted according to the overarching themes. Accordingly, coding facilitates the management of the vast amount of data that has been collected. It is important to allude to the relationship between codes and themes.

3. Revising themes is about combining, separating, refining, or discarding initial themes. This relates mainly to the inductive approach to thematic analysis. Data within the themes should cohere together meaningfully and be clear and identifiable as regards the distinction between these themes. A thematic 'map' is generated from this step.

4. Producing the report involves transforming the analysis into an interpretable piece of writing by using vivid and compelling data extracts that relate to the overarching themes, research questions, and literature. This is a fundamental step for supporting future comparative research and cross-case analysis (Yin 1984; Patton 2012). The report must go beyond a mere description of the preconceived themes and portray an analysis supported with the empirical evidence that addresses the research questions.

This analytical strategy has allowed to analyze the selected cases considering the different perspectives of multiple observers. Moreover, the final description of the process has gained greater strength thanks to the triangulation made possible by the use of multiple sources of evidence (George and Bennett 2005; Yin 1984; Voss et al. 2002).

As to the results from the thematic analysis of the four case studies, the interested reader can be directed to Bibri and Krogstie (2020d). The integrated framework illustrated in Fig. 3 was derived based on the thematic analysis in terms of the core dimensions of compact cities, eco-cities, data-driven smart cities, and environmentally datadriven smart sustainable cities. It attempts to capture in a structured manner the underlying components of the novel model for data-driven smart sustainable cities of the future. In this respect, there are four basic categories of criteria that are used in defining the data-driven smart sustainable city of the future, namely compact urban strategies, ecological urban strategies, data-driven technologies and solutions for sustainability, and data-oriented competences. The basic idea revolves around the integration of the strategies of sustainable cities with the applied solutions of data-driven smart cities. This is predicated on the assumption that big data technologies and their novel applications associated with the informational landscape of smart cities have great potential to improve and advance the design strategies and technology solutions pertaining to the physical landscape of sustainable cities in terms of their contribution to the environmental, economic, and social goals of sustainability. 


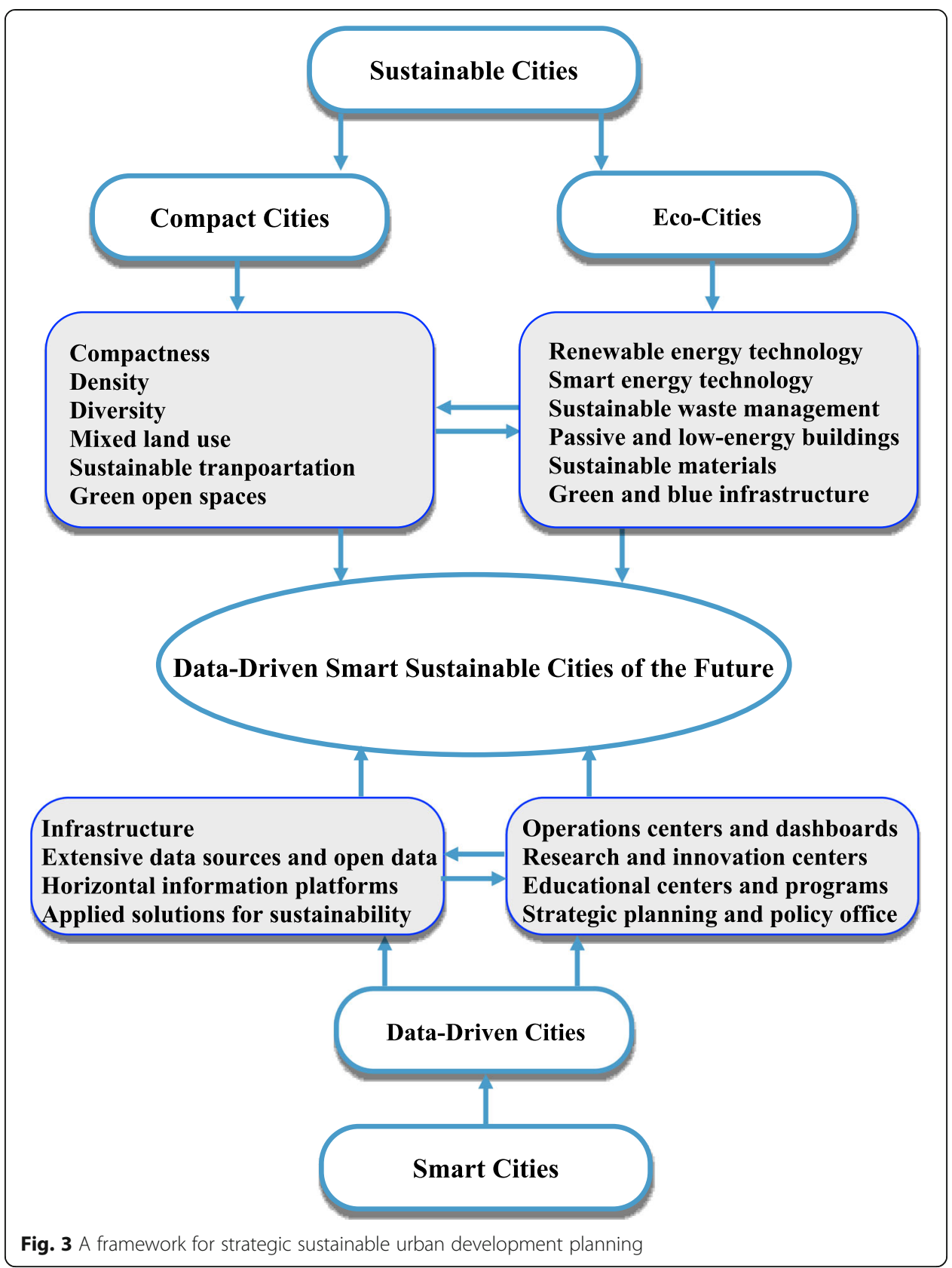

\section{Conclusion}

Backcasting belongs to the normative category of futures studies. A number of futures studies using the normative backcasting approach have highlighted its efficacy in indicating pathways for sustainability transitions in terms of the ability to produce a desired result, thereby its role and relevance in supporting policymakers and facilitating and guiding their actions with respect to strategic sustainable development. The purpose of the backcasting-oriented futures study is to create knowledge that can be used to guide complex urban transitions towards urban sustainability in an increasingly technologized and urbanized world. In this sense, backcasting can be viewed as changing mindsets about how sustainable cities function by being designed in ways that allow to monitor, understand, analyze and plan their systems to improve sustainability, efficiency, 
resilience, equity, and the quality of life. In the data-driven smart sustainable city of the future as a complex system, backcasting is an effective approach to align various measures with each other and to ensure that each activity is the logical platform for the next one.

This paper described, discussed, and justified the methodological framework applied in the futures study concerned with data-driven smart sustainable urbanism as a form of transformative change towards sustainability. The novelty of this work lies in the integration of a set of principles underlying several normative backcasting approaches with descriptive case study design to devise a framework for strategic urban planning whose core objective is clarifying which city model is desired and working towards that goal.

Visionary images of a long-term future based on normative backcasting can spur innovative thinking about and accelerate the movement towards achieving the goals of sustainability. The data-driven smart sustainable city of the future as a new paradigm of urbanism can be seen as the most important arena for sustainability transitions in the era of big data. It offers a clear prospect to instigate a major transformative change by synergistically linking the agendas of urban development, sustainable development, and technological development to add a whole new dimension to sustainability in terms of its advancement. This kind of drastic change requires a multifaceted process of strategic planning with an innovative vision that takes the sustainable city from its present state to a desirable future state. Backcasting as the most suitable approach to strategic sustainability planning can play a pivotal role in this regard by determining decisive steps and guiding decision-making processes to achieve the long-term desired outcomes. Moreover, it allows for a better understanding of future opportunities and exploring the implications of alternative development paths that can be relied on to mitigate or avoid the potentially negative impacts of the future. It is a commonly held view that strategic planning based on normative backcasting scenarios can change development paths. When applied in sustainability planning, backcasting can also increase the likelihood to envision certain changes. The interest in the pursuit of the data-driven smart sustainable city of the future is motivated by the aspiration to influence, inspire, as well as transform the future of the sustainable city by changing the path of its development or redirecting its transition to a better future in the light of the emerging paradigm of big data science and analytics. Therefore, it is scholarly worthy to venture some thoughts about where it might be useful to channel the efforts now and in the future in the sphere of what has been termed "data-driven smart sustainable urbanism."

The outcomes of the four case studies carried out are intended to guide and inform the futures study in terms of the underlying components of the novel model for datadriven smart sustainable cities of the future. By carefully studying any unit of a certain universe, we are in terms of knowing some general aspects of it, at least a perspective that guides ongoing or subsequent research (Wieviorka 1992). Case studies often represent the first scholarly toe in the water in the new areas of research. In this context, the six cases were investigated to identify the design strategies of sustainable cities and the data-driven solutions of smart cities that are needed to develop the data-driven smart sustainable city of the future as a new paradigm of urbanism. 
The application of and sound debate about the value, validity, and capability of case study research have strengthened the efficacy of the case study approach as a powerful form of qualitative research. Moreover, case studies are useful for formulating concepts, which are an important aspect of theory construction (Mahoney 2010). The concepts used in qualitative research tend to have higher conceptual validity than concepts used in quantitative research due to conceptual stretching: the unintentional comparison of dissimilar cases (George and Bennett 2005) Case studies add descriptive richness (Collier 2011). However, a commonly described limit of case studies is that they do not lend themselves to generalizability. Additionally, George and Bennett (2005) note that a common problem in case study research is that of reconciling conflicting interpretations of the same.

The case study and backcasting approaches are both regarded as a tool with which theories can be supported and their effects can be demonstrated, as well as facts can be developed. The purpose of analyzing and evaluating the six cases associated with the futures study is to provide the theoretical and practical foundations necessary for backcasting the future phenomenon of the data-driven smart sustainable city. In this respect, it is important first and foremost to define which characteristics of the future state of this phenomenon are meaningful, beneficial, and interesting, and should therefore be incorporated in the backcasting (see Bibri and Krogstie 2020d for further details). This involves both the theoretical underpinnings and the emerging practices that are of pertinence and importance as a basis for the backcasting. With respect to the former, the material needed to make the backcasting depends on how strong the theoretical frameworks we have about the envisioned phenomenon of the data-driven smart sustainable city and its internal relationships from a conceptual, disciplinary, and discursive perspective (see Bibri 2018a, d, 2019a, c, d, 2020a; Bibri and Krogstie 2016, 2017b for further details). Commonly, quite a strong basis for backcasting any future phenomenon is available when there are frameworks that can explain, support, and justify that phenomenon. On the whole, this scholarly backcasting endeavor combines the theoretical analysis and the empirical investigation to develop the data-driven smart sustainable city of the future.

\section{Abbreviations}

CTA: Constructive Technology Assessment; FSSD: Framework for Strategic Sustainable Development; ICT: Information and Communication Technology; IOT: Internet of Things; SDG: Sustainable Development Goal; STD: Sustainable Technology Development; SRS: Stockholm Royal Seaport; SASD: Strategic Approach to Sustainable Development: SUMP: Sustainable Urban Mobility Planning; TNS: The Natural Step

Acknowledgements

Not applicable.

Author's contributions

The author read and approved the final version of this manuscript.

Funding

The author received no financial support for the research, authorship, and/or publication of this article.

Availability of data and materials

Not applicable.

Competing interests

The author declared no potential conflicts of interest with respect to the research, authorship, and/or publication of this article. 
Received: 23 August 2020 Accepted: 23 October 2020

Published online: 03 December 2020

\section{References}

Achaerandio, R. et al. (2011) "Smart cities analysis in Spain" http://www.idc.com [Accessed 25 Jun 2015]

Ajuntament de Barcelona. (2011) "Barcelona to hold an international summit on urban innovation". http://w110.bcn.cat

Ajuntament de Barcelona. (2012) "Barcelona acull el XXè Congrés de CIDEU, la xarxa iberoamericana que promou el desenvolupament estratègic urbà". http://w110.bcn.cat

Ajuntament de Barcelona. (2013) "The Mayor promotes Barcelona in the United States" http://w110.bcn.cat

Ajuntament de Barcelona. (2014a) "The Barcelona Smart City website". http://smartcity.bcn.cat/en

Ajuntament de Barcelona. (2014b) "Barcelona, a benchmark smart city". http://w110.bcn.cat

Ajuntament de Barcelona. (2014c) "L'Alcalde Trias assegura que la principal prioritat del que queda de mandat és crear llocs de treball". http://premsa.bcn.cat

Akande A, Gomes P, Cabral P (2018) The Lisbon ranking for smart sustainable cities in Europe. Sustain Cities Soc 44(2019): $475-487$

Åkerman J (2005) Sustainable air transport - on track in 2050. Transportation Research-D10 (2):111-126.

Akerman J, Höjer M (2006) How much transport can the climate stand?_-Sweden on a sustainable path in 2050. Energy Policy 34(14):1944-1957

Anderson KL (2001) Reconciling the electricity industry with sustainable development: backcasting - a strategic alternative. Futures 33:607-623.

Anthony S, Jack S (2009) Qualitative case study methodology in nursing research: an integrative review. J Adv Nurs 65(6): 1171-1181. https://doi.org/10.1111/j.1365-2648.2009.04998.x

Baldersheim H, Ståhlberg K (2002) From guided democracy to multilevel governance: trends in central-local relations in the Nordic countries. Local Gov Stud 28(3):74-90

Banister D, Stead D (2004) The impact of ICT on transport. Transp Rev 24(5):611-632

Banister D, Stead D, Steen P, Dreborg KH, Akerman J, Nijkamp P et al (2000) European transport policy and sustainable mobility. Spon Press, London

Batty M (2013) Big data, smart cities and city planning. Dialogues Hum Geography 3(3):274-279

Bibri SE (2018a) Smart sustainable cities of the future: the untapped potential of big data analytics and context aware computing for advancing sustainability. Springer, Germany, Berlin

Bibri SE (2018b) The loT for smart sustainable cities of the future: an analytical framework for sensor-based big data applications for environmental sustainability. Sustain Cities aSoc 38:230-253

Bibri SE (2018c) Backcasting in futures studies: a synthesized scholarly and planning approach to strategic smart sustainable city development. Eur J Futures Res 6(13):1-27

Bibri SE (2018d) A foundational framework for smart sustainable city development: theoretical, disciplinary, and discursive dimen- sions and their synergies. Sustain Cities Soc 38:758-794

Bibri SE (2019a) Big data science and analytics for smart sustainable urbanism: unprecedented paradigmatic shifts and practical advancements. Springer, Germany, Berlin

Bibri SE (2019b) The anatomy of the data-driven smart sustainable city: instrumentation, datafication, computerization and related applications. J Big Data 6:59

Bibri SE (2019c) The sciences underlying smart sustainable urbanism: unprecedented paradigmatic and scholarly shifts in light of big data science and analytics. Smart Cities 2(2):179-213

Bibri SE (2019d) Data-driven smart sustainable Urbanism: The intertwined societal factors underlying its materialization. Success, Expansion, Evol Geojournal. https://doi.org/10.1007/s10708-019-10061-x

Bibri SE (2020a) Advances in the leading paradigms of urbanism and their amalgamation: compact cities, eco-cities, and data-driven smart cities, vol 2020. Springer Nature Switzerland AG, Cham

Bibri SE (2020b) The eco-city and its core environmental dimension of sustainability: green energy technologies and their integration with data-driven smart solutions. Energy Inform 3(4). https://doi.org/10.1186/s42162-020-00107-7

Bibri SE (2020c) Compact urbanism and the synergic potential of its integration with data-driven smart urbanism : An extensive interdisciplinary literature review, Journal of Land Use Policy 97:1-20

Bibri SE (2020d) Data-driven environmental solutions for smart sustainable cities: strategies and pathways for energy efficiency and pollution reduction. Euro-Mediterr J Environ Integr 5, 66 (2020). https://doi.org/10.1007/s41207-020-00211-w

Bibri SE, Krogstie J (2016) On the social shaping dimensions of smart sustainable cities: a study in science, technology, and society. Sustain Cities Soc 29:219-246

Bibri SE, Krogstie J (2017a) ICT of the new wave of computing for sustainable urban forms: their big data and context-aware augmented typologies and design concepts. Sustain Cities Soc 32:449-474

Bibri SE, Krogstie J (2017b) The core enabling technologies of big data analytics and context-aware computing for smart sustainable cities: a review and synthesis. J Big Data 4(38):1-50

Bibri SE, Krogstie J (2018) The big data deluge for transforming the knowledge of smart sustainable cities: a data mining framework for urban analytics. In Proceedings of the 3D Annual International Conference on Smart City Applications, ACM, 11-12 Oct, Tetouan, Morocco

Bibri SE, Krogstie J (2019a) A scholarly backcasting approach to a novel model for smart sustainable cities of the future: strategic problem orientation. City, Territory, Architecture 6(3):1-27

Bibri SE, Krogstie J (2019b) Generating a vision for smart sustainable cities of the future: a scholarly backcasting approach. Eur J Futures Res 7(5):1-20

Bibri SE, Krogstie J (2020a) Smart eco-city strategies and solutions for sustainability: the cases of royal seaport. Stockholm, Western Harbor, Malmö, Sweden, Urban Sci 4(1):1-42

Bibri SE, Krogstie J (2020b) The emerging data-driven Smart City and its innovative applied solutions for. sustainability: the cases of London and Barcelona. Energy Inform 3:5. https://doi.org/10.1186/s42162-020-00108-6

Bibri SE, Krogstie J (2020c) Environmentally data-driven smart sustainable cities: applied innovative solutions for energy efficiency, pollution reduction, and urban metabolism. Energy Inf In Press 
Bibri SE, Krogstie J (2020d) Data-driven smart sustainable cities of the future: a novel model of urbanism and its core dimensions, strategies, and solutions. J Futures Stud In Press

Bibri SE, Krogstie J, Kärrholm M (2020) Compact city planning and development: emerging practices and strategies for achieving the goals of sustainability. Dev Built Environ 4:1-2

Börjeson L, Höjer M, Dreborg KH, Ekvall T, Finnveden G (2006) Scenario types and techniques: towards a user's guide. Futures 38(7):723-739

Bossel H (2004) Systeme, dynamik, simulation: Modellbildung, analyze und simulation komplexer systeme. Books on Demand, Norderstedt

Braun V, Clarke V (2006) Using thematic analysis in psychology. Qual Res Psychol 3:77-101

Brown L (2008) A review of the literature on case study research. Can J New Scholars Educ 1(1):1-13

Buder S 2019, These are the world's most environmentally friendly countries, https://epi.yale.edu/epi-toplin

Carlsson-Kanyama, A., Dreborg, K. H., Eenkhorn, B. R., Engström, R., \& Falkena, B. (2003) Image of everyday life in the future sustainable city: Experiences of back-casting with stakeholders in five European cities. The Environmental Strategies Research Group (Fms)-report 182, The Royal Institute of Technology, Stockholm. Report available at /react-text www. infra.kth.sereact-text:563

Chatterjee K, Gordon A (2006) Planning for an unpredictable future: transport in Great Britain in 2030. Transp Policy 13(2006): $254-264$

Clark WC (2007) Sustainability science: a room of its own. Proc Nat Acad Sci U S A 104:1737-1738

Clark WC, Dickson NM (2003) Sustainability science: the emerging research program. Proc Natl Acad Sci U S A 100(14):8059-8061

Cohen, B. (2012a) "The 10 smartest cities on the planet". http://www.fastcoexist.com [Accessed 25 Jun 2015]

Cohen, B. (2012b) "The 10 smartest european cities". http://www.fastcoexist.com [Accessed 25 Jun 2015]

Cohen, B. (2014) "The 10 smartest cities in Europe". http://www.fastcoexist.com [Accessed 25 Jun 2015]

Collier D (2011) Understanding process tracing. PS: Political Sci Politics 44(04):823-830. https://doi.org/10.1017/ S1049096511001429 ISSN 1049-0965

Creswell JW, Hanson WE, Clark P, Vicki L, Morales A (2007) Qualitative research designs: selection and implementation. Couns Psychol 35(2):236-264

Creswell JW (2014) Research design: qualitative, quantitative and mixed methods approaches, 4th edn. Sage, Thousand Oaks de Vries BJM (2013) Sustainability science. Cambridge University Press, Universiteit Utrecht, The Netherlands

Dreborg KH (1996) Essence of backcasting. Futures 28(9):813-828

Dryzek JS (2005) The politics of the earth. Environmental discourses, 2nd edn. Oxford University Press, Oxford

Eckstein H (1975) Case study and theory in political science. In: Greenstein F, Polsby N (eds) The handbook of political science: Strategies of inquiry, vol 7. Addison-Wesley, Reading, pp 79-137

Eden Strategy Institute. (2018) Report, https://www.smartcitygovt.com

Elliott H, Brannen J, Phoenix A, Barlow A, Morris P, Smart C, Smithson J, Bauer E (2013) Analysing qualitative data in groups: process and practice. National Centre for Research Methods Working Paper, NCRM/NOVELLA, Southampton

European Commission. (2014) "Barcelona is iCapital of Europe". http://europa.eu [Accessed 13 Mar 2014]

European Green Capital (2009) The Expert Panel's Evaluation Work Final Recom- Mendations for the European Green Capital Award of 2010 and 2011. European Commission, Brussels

Farquhar JD (2012) What is case study research? In: Farquhar JD (ed) Case study research for business. Sage, London, pp 314. https://doi.org/10.4135/9781446287910.n2

Flyvbjerg B (2011) Case study. In: Denzin NK, Lincoln YS (eds) The Sage handbook of qualitative research, 4th. edn. Sage, Thousand Oaks, pp 301-316

Green K, Vergragt P (2002) Towards sustainable households: a methodology for developing sustainable technological and social innovations. Futures 34:381-400.

George AL, Bennett A (2005) Case studies and theory development in the social sciences. MIT Press, Cambridge

Höjer M, Gullberg A, Pettersson R (2011) Backcasting images of the future city—-time and space for sustainable development in Stockholm. Technol Forecast Soc Chang 78(5):819-834

Höjer M, Mattsson L (2000) Determinism and backcasting in future studies. Futures 32:613-634

Holmberg J (1998) Backcasting: a natural step in operationalizing sustainable development. GreenerManag Int 23:30-51

Holmberg J, Robèrt KH (2000) Backcasting from non-overlapping sustainability principles: a framework for strategic planning. Int J Sust Dev World 74:291-308

Holloway, I., \& Todres, L. (2003) The status of method: Flexibility, consistency and coherence. Qualitative Research, 3(3), 345-357.

Holmstedt, L., Brandt, N. \& Robert, K. H. (2017) Can Stockholm Royal Seaport be part of the puzzle towards global sustainability? From local to global sustainability using the same set of criteria. Journal of Cleaner Production,140, 72-80.

Kalbro T, Lindgren E, Røsnes A (2010) Nær utakt - Plan og bygnings lovsreformer i Norge og Sverige [Planning and Building Act reforms in Norway and Sweden]. Kartog Plan 70(1):27-45

Johansson C (2018) City of S.: Interview Claes Johannesson, smart city Stockholm, Project leader

Kates R, Clark W, Corell R, Hall J, Jaeger C (2001) Sustainability science. Science (Science) 292(5517):641-642

Kitchin R (2014) The real-time city? Big data and smart urbanism. Geo J 79:1-14

Kitchin R (2016) The ethics of smart cities and urban science. Phil Trans R Soc A 374:20160115

Kramers A, Wangel J, Höjer M (2016) Governing the smart sustainable city: the case of the Stockholm Royal Seaport. In: Proceedings of ICT for sustainability 2016, vol 46. Atlantis Press, Amsterdam, pp 99-108

Lijphart A (1971) Comparative politics and the comparative method. Am Polit Sci Rev 65(2):682-693

Lindström B, Eriksson B (1993) Quality of life among children in the Nordic countries. Qual Life Res 2(1):23-32

Ling T (2002) Contested health futures. In: Brown N, Rappet B, Webster A (eds) Contested futures: a sociology of prospective techno-science. Ashgate, Aldersho

Mahoney J (2010) After KKV: the new methodology of qualitative research. World Polit 62(1):120-147. https://doi.org/10.1017/ S0043887109990220 ISSN 1086-3338

Malmö City (2015) Western Harbor, Current Urban Planning. Available online: https://malmo.se/download/18.76b7688614 bb5ccea09157af/1491304414891/Current+urban+development+in+Western+Harbour+\%282015\%29.pdf [Accessed 21 May 2019] 
Manville, C. et al. (2014) "Mapping smart city in the EU". http://www.europarl.europa.eu

Merriam SB (2009) Qualitative research: a guide to design and implementation, 2nd edn. Jossey-Bass, San Francisco

Miola A (2008) Backcasting approach for sustainable mobility. European Commission, Joint Research Center, Institute for Environment and Sustainability

Mol APJ (2000) Ecological modernization and the global economy. Glob Environ Politics 2(2):92-115 ISSN 1526-3800

Mora L, Bolici R (2016) The development process of smart city strategies: the case of Barcelona. In: Rajaniemi J (ed) Re-city: future city - combining disciplines, Juvenes print

Mills, Jane (2014) Methodology and methods. In Jane Mills \& Melanie Birks (Eds.), Qualitative methodology: A practical guide (pp.31-47) Thousand Oaks, CA: Sage

Nikitin K, Lantsev N, Nugaev A, Yakovleva A (2016) Data-driven cities: from concept to applied solutions. PricewaterhouseCoopers (PwC) http://docplayer.net/50140321-From-concept-to-applied-solutions-data-driven-cities.html

Noori N, Hoppe T, de Jong M (2020) Classifying pathways for Smart City development: comparing design, governance and implementation in Amsterdam, Barcelona, Dubai, and Abu Dhabi. Sustainability 12:4030

Patton MQ (2012) Qualitative research and evaluation methods, 3rd edn. SAGE Publications, Thousand Oaks

Pasichnyi O, Levihn F, Shahrokni H, Wallin J, Kordas O (2019) Data-driven strategic planning of building energy retrofitting: The case of Stockholm. J Clean Prod 233:546-560

Quist, J (2007) Backcasting for a sustainable future: the impact after 10 years, Ph.D. thesis, Faculty of Technology, policy and management, Delft University of Technology, Delft

Quist J, Knot M, Young W, Green K, Vergragt P (2001) Strategies towards sustainable households using stakeholder workshops and scenarios. Int J Sustain Dev 4:75-89

Quist J, Vergragt PJ (2006) Past and future of backcasting: the shift to stakeholder participation and proposal for a methodological framework. Futures 38(2006):1027-1045

Robert, K.H. (2000) Tools and concepts for sustainable development, how to they relate to a general framework for sustainable development, and to each other? Journal of Cleaner Production 8 (2000) 243-254

Robinson J (1982) Energy backcasting — a proposed method of policy analysis. Energy Policy 12(1982):337-344

Robinson J (1990) Futures under glass: a recipe for people who hate to predict. Futures 22(8):820-842

Rose L, Ståhlberg C (2005) The Nordic countries: still the 'promised land'? In: Denters B, Rose L (eds) Comparing local governance: trends and developments. Palgrave McMillan

Rotmans J, Kemp R, van Asselt M (2001) More evolution than revolution: transition management in public policy. Foresight 3(1)

Schwandt TA (2001) Dictionary of qualitative inquiry, 2nd edn. SAGE, Thousand Oaks

Seawright J, Gerring J (2014) Case selection techniques in case study research: a menu of qualitative and quantitative options. In: Case Studies. SAGE Publications Ltd, p II213. https://doi.org/10.4135/9781473915480.n31 ISBN 978-1-4462-7448-4

Simons H (2009) Case study research in practice. Sage, Los Angeles

Sinaeepourfard AJ, Garcia XM-B, Marín-Tordera E, Cirera J, Grau G, Casaus F (2016) Estimating Smart City sensors data generation current and future data in the City of Barcelona. In: Proceedings of conference: the 15th IFIP annual Mediterranean ad hoc networking workshop

Stake RE (1995) The art of case study research. SAGE, Thousand Oaks

Stake RE (2005) Qualitative case studies. In: Denzin NK, Lincoln YS (eds) The SAGE handbook of qualita- tive research, 3rd edn. SAGE, Thousand Oaks, pp 443-466

Stake RE (2006) Multiple case study analysis. Guilford, New York

Stewart A (2014) Case study. In: Mills J, Birks M (eds) Qualitative methodology: a practical quide. Sage, Thousand Oaks, pp 145-159

Stockholm City (2009) Stockholm Royal Seaport: Vision 2030. https://international.stockholm.se/globalassets/ovriga-bilder-ochfiler/visionsrs2030_medium.pdf

Stockholm City (2018) https://vaxer.stockholm/globalassets/tema/oversiktplan-ny_light/english_stockholm_city_plan.pdf

Stockholm City (2020) Royal Seaport Stockholm. https://international.stockholm.se/city-development/the-royal-seaport/

Stockholm City (2010) Övergripande program för miljö och hållbar stadsutveckling i Norra Djurgårdsstaden. Stockholm City Council, Stockholm

Sun Y, Du Y (2017) Big data and sustainable cities: applications of new and emerging forms of geospatial data in urban studies. Open Geospatial Data, Softw Stand 2:24 https://doi.org/10.1186/s40965-017-0037-0

Shahrokni, H., Levihn, F., \& Brandt. N. (2014a) Big meter data analysis of the energy efficiency potential in Stockholm's building stock, Energy and Buildings. 78:153-164

Shahrokni, H., van der Heijde, B., Lazarevic, D., \& Brandt. N. (2014b) Big data GIS analytics towards efficient waste management in Stockholm. In ICT4S-ICT for Sustainability. Stockholm: Alantis Press

Shahrokni, H., Årman, L., Lazarevic, D., Nilsson, A., \& Brandt, N. (2015a). Implementing smart urban metabolism in the Stockholm Royal Seaport: smart city SRS. Journal of Industrial Ecology, 19 (5):917-929

Shahrokni, H., Lazarevic D., \& Brandt, N. (2015b) Smart Urban Metabolism: Towards a real-time understanding of the energy and material flows of a city and its citizens, Journal of Urban Technology, 22, (1), 65-86.

The Norden (2008) The Nordic energy markets and environment. Nordic Council of Ministers, Copenhagen, Copenhagen

Thomas G (2011) A typology for the case study in social science following a review of definition, discourse, and structure. Qual Inq 17(6):511-521. https://doi.org/10.1177/1077800411409884

Tuominent A, Tapio P, Jarvi T, Banister D (2014) Pluralistic backcasting: Integrating multiple visions with policy packages for transport climate policy. Futures 60:41-58

The Nordics (2017) Smart City Solutions. Available online: http://www.nordicpavilion.org/stockholm-royal-seaport-2018/ [Accessed 19 Oct 2019]

United Nations (2015a). Transforming Our World: the 2030 Agenda for Sustainable Development. New York. Available at: https://sustainabledevelopment.un.org/post2015/transformingourworld

United Nations (2015b) Habitat III Issue Papers, 21—Smart cities (V2.0), New York. Available at: https://unhabitat.org/issuepapers-and-policy-units [Accessed 2 May 2017]

United Nations (2015c) Big Data and the 2030 agenda for sustainable development. Prepared by A. Maaroof. Available at: https:// www.unescap.org/sites/default/files/1_Big\%20Data\%202030\%20Agenda_stock-taking\%20report_25.01.16.pdf

Vergragt PJ, Quist J (2011) Backcasting for sustainability: introduction to the special issue 1. Technol Forecast Soc Chang 78(5):747-755 
Voss C et al (2002) Case research in operations management. In: International Journal of Operations \& Production Management. 22/2, pp 195-219

Wangel J (2011) Exploring social structures and agency in backcasting studies for sustainable development. Technological Forecasting Soc Change 78(5):872-882

Weaver P, Jansen L, van Grootveld G, van Spiegel E, Vergragt P (2000) Sustainable technology development. Greenleaf Publishers, Sheffield

White HC (1992) Cases are for identity, for explanation, or for control. In: Ragin CC, Becker HS (eds) What is a case? Exploring the foundations of social inquiry. Cambridge University Press, New York, pp 443-466

Wieviorka M (1992) Case studies: history or sociology? In: Ragin CC, Becker HS (eds) What is a case? Exploring the foundations of social inquiry.Cambridge University Press, Cambridge, pp 159-172

Wouter HNE, Robin E, Efthymios C (2018) The internet of things as smart city enabler: the cases of Palo Alto, Nice and Stockholm. In: 18th IFIP conference on e-business, e-services, and e-society, I3E 2019, 18-19 Sept, Trondheim Yin RK (1984) Case study research: design and methods. SAGE Publications, Thousand Oaks

Yin RK (2009) Case study research: design and methods, 4th edn. Sage, London

Yin RK (2014) Case study research: design and methods. Sage, Los Angeles

Yin RK (2017) Case study research and applications: design and methods, 6th edn. SAGE Publications, Inc

\section{Publisher's Note}

Springer Nature remains neutral with regard to jurisdictional claims in published maps and institutional affiliations.

Submit your manuscript to a SpringerOpen ${ }^{\circ}$ journal and benefit from:

- Convenient online submission

- Rigorous peer review

- Open access: articles freely available online

- High visibility within the field

- Retaining the copyright to your article 